\title{
Article
}

\section{Human IPSC-Derived Model to Study Myelin Disruption}

\author{
Megan Chesnut ${ }^{1}$, Hélène Paschoud ${ }^{2}$, Cendrine Repond ${ }^{2}{ }^{-}$, Lena Smirnova ${ }^{1}$, Thomas Hartung 1,3, \\ Marie-Gabrielle Zurich ${ }^{2,4}\left(\mathbb{D}\right.$, Helena T. Hogberg ${ }^{1, *}$ and David Pamies $1,2,4, *$ (D) \\ 1 Center for Alternatives to Animal Testing (CAAT), Johns Hopkins Bloomberg School of Public Health, 615 N \\ Wolfe St., Baltimore, MD 21205, USA; meganechesnut@gmail.com (M.C.); lena.smirnova@jhu.edu (L.S.); \\ thartun1@jhu.edu (T.H.) \\ 2 Department of Biomedical Sciences, University of Lausanne, CH-1005 Lausanne, Switzerland; \\ helene.paschoud@hotmail.com (H.P.); cendrine.repond@unil.ch (C.R.); \\ marie-gabrielle.zurichfontanellaz@unil.ch (M.-G.Z.) \\ 3 Center for Alternative to Animla Testing Europe, University of Konstanz, 78464 Konstanz, Germany \\ 4 Swiss Centre for Applied Human Toxicology (SCAHT), 4055 Basel, Switzerland \\ * Correspondence: Hhogber2@jhu.edu (H.T.H.); david.pamies@unil.ch (D.P.)
}

check for updates

Citation: Chesnut, M.; Paschoud, H.; Repond, C.; Smirnova, L.; Hartung, T.; Zurich, M.-G.; Hogberg, H.T.; Pamies, D. Human IPSC-Derived Model to Study Myelin Disruption. Int. J. Mol. Sci. 2021, 22, 9473. https://doi.org/ $10.3390 /$ ijms 22179473

Academic Editor: Irmgard Tegeder

Received: 29 July 2021

Accepted: 28 August 2021

Published: 31 August 2021

Publisher's Note: MDPI stays neutral with regard to jurisdictional claims in published maps and institutional affiliations.

Copyright: (c) 2021 by the authors. Licensee MDPI, Basel, Switzerland. This article is an open access article distributed under the terms and conditions of the Creative Commons Attribution (CC BY) license (https:// creativecommons.org/licenses/by/ $4.0 /)$.

\begin{abstract}
Myelin is of vital importance to the central nervous system and its disruption is related to a large number of both neurodevelopmental and neurodegenerative diseases. The differences observed between human and rodent oligodendrocytes make animals inadequate for modeling these diseases. Although developing human in vitro models for oligodendrocytes and myelinated axons has been a great challenge, 3D cell cultures derived from iPSC are now available and able to partially reproduce the myelination process. We have previously developed a human iPSCderived 3D brain organoid model (also called BrainSpheres) that contains a high percentage of myelinated axons and is highly reproducible. Here, we have further refined this technology by applying multiple readouts to study myelination disruption. Myelin was assessed by quantifying immunostaining/confocal microscopy of co-localized myelin basic protein (MBP) with neurofilament proteins as well as proteolipid protein 1 (PLP1). Levels of PLP1 were also assessed by Western blot. We identified compounds capable of inducing developmental neurotoxicity by disrupting myelin in a systematic review to evaluate the relevance of our BrainSphere model for the study of the myelination/demyelination processes. Results demonstrated that the positive reference compound (cuprizone) and two of the three potential myelin disruptors tested (Bisphenol A, Tris(1,3-dichloro2-propyl) phosphate, but not methyl mercury) decreased myelination, while ibuprofen (negative control) had no effect. Here, we define a methodology that allows quantification of myelin disruption and provides reference compounds for chemical-induced myelin disruption.
\end{abstract}

Keywords: developmental neurotoxicity; neurotoxicity; organotypic; organoid; myelin; developmental diseases; oligodendrocytes

\section{Introduction}

Myelination is the process in which myelin sheaths are formed by oligodendrocytes in the central nervous system (CNS) and Schwann cells in the peripheral nervous system (PNS). Myelin sheaths consist of a vast variety of lipids and proteins [1]. Oligodendrocytes, by forming a plasma membrane extension that wraps neuronal axonal segments, generate this structure necessary for the saltatory impulse propagation [2,3]. As half of the human brain is composed of myelinated axons (white matter), damage or loss of this structure or to the producing cells could be detrimental to the central nervous system. Many neurodegenerative diseases and neurological disorders are associated with impaired myelin integrity, including multiple sclerosis, acute-disseminated encephalomyelitis, acute hemorrhagic leucoencephalitis, Alzheimer's, Parkinson's, and Huntington's diseases [4-7] and more recently Williams syndrome [4-9]. Myelin deficits have shown social impairments, motor abnormalities and poor white matter functioning [9]. The study of myelin has mainly been 
conducted in animals, due to the difficulty of modeling myelination in vitro [10]. However, there are clear differences between rodents and humans [11]. Differential gene expression analysis revealed 244 genes expressed in human oligodendrocytes that are not expressed in their mouse counterparts [12]. In addition, the protein composition of myelin is not fully conserved across species [13]. Thus, there is a need to develop models that better represent human myelin physiology.

The brain is the most complex organ in the body in terms of development and function, making it extremely vulnerable to insults [14]. Small changes during development may lead to severe neurological problems. Moreover, infants and children have higher air, food, and water intake per body weight [15,16], immature metabolism [17,18], and certain behaviors such as hand-to-mouth, crawling, and playing close to the ground [16,17], making them more susceptible to chemically-induced brain damage than adults $[15,16]$. Perturbations to proliferation, migration, cell composition, neuronal network formation, and cell organization, for example, can have detrimental consequences for the function of the brain $[18,19]$. Most of the time, these effects are not detectable shortly after birth but manifest later in life [20].

Studies between 1997 and 2008 showed a 17\% increase in the prevalence of developmental disabilities in children in that decade compared to the previous [21]. Centers for Disease Control and Prevention (CDC), for example, estimated that one in 54 children born in the US was diagnosed with autism spectrum disorder (ASD) [22], and reported that $9.4 \%$ (6.1 million) children in United States were diagnosed with attention deficit/hyperactivity disorder (ADHD) in 2016 [23]. In addition to improved diagnostics, medical advances, and improved survival rates of (pre-term) newborns [21,24], environmental contaminants may play a substantial role $[18,20,25]$ in this increase. Despite enhanced research in the last years, the majority of etiologies of these neurodevelopmental disorders are still unknown $[20,26]$, while concerns about the influence of environmental contributions are rising [27-29]. Furthermore, some evidence indicates that environmental chemicals, e.g., lead, arsenic, and methylmercury, can contribute to subclinical neurodevelopmental toxicity (such as decreased cognitive function) $[20,30,31]$.

The extensive costs, time, and difficulty to interpret data from current in vivo testing guidelines for developmental neurotoxicity (DNT), makes it one of the least tested toxicological hazards [32,33]. Therefore, the lack of information for most of the chemicals present on the market, including the high-volume production chemicals [34,35], becomes a very important public health concern. The use of in vitro methods present a more costeffective and potentially more human-relevant alternative for DNT [35] - moving from observational animal experimentation to a mechanism-based science [36-40]. A comprehensive in vitro DNT strategy consisting of a testing battery of assays that recapitulate key processes during brain development, such as migration, proliferation, differentiation, synaptogenesis, myelination, apoptosis, and neuronal network formation, has been suggested [19,41-43]. However, assessment of the myelination process is challenging due to the lack of suitable in vitro models that can recapitulate the in vivo situation. Various models that evaluate oligodendrocyte toxicity can be found in the literature and have been reviewed elsewhere [10]. These models are primarily monocultures of oligodendrocyte precursors or oligodendrocytes, deprived of the cell-cell interactions with neurons required to achieve myelination. Although co-culturing of neurons and oligodendrocytes exist [44-46], most of these cultures are still in a monolayer condition, which difficult myelination. However, some co-cultures have been able to generate compact myelin over neuronal axons [47,48] even using stem cell-derived human [49]. Another in vitro models exhibit intense myelination, such as ex vivo rodent brain slices [50-52], rat aggregating brain cell cultures [53-56], or microfluidics cell culture systems [57], but they are all animalbased. Since myelin composition is not well conserved across species [13], DNT testing absolutely requires human cell-based models. Human IPSC-derived models to study myelin disruption have been revised elsewhere [58]. Some new human models combining iPSC and novel in vitro cultures technologies [59-63] have emerged, but only two study 
showed quantitative assessment [63]. Here, we provide an extensive evaluation of myelin quantification and adequate reference compounds for the assessment of myelin disruption.

The organotypic human BrainSpheres model, developed at Johns Hopkins University [61,64], mimics several steps of brain development [61]. The model, derived from iPSCs, is reproducible in terms of size, shape, and cell composition; contains most major brain cell types, such as different types of neurons, oligodendrocytes, and astrocytes [61]; and presents spontaneous neuronal electrical activity, with around $40 \%$ of myelinated axons [61]. Previous results have shown its usefulness for studying pharmacotoxicology [65], brain diseases [66], neurotoxicology [67], and DNT [68,69]. For the latter, the model has shown to adequately assess deleterious chemical effects on key processes of brain development, such as neurite outgrowth, synaptogenesis, and oligodendrocyte differentiation [68,69].

The aim of this study was to evaluate the potential of the BrainSphere model to serve as a myelination test system and to evaluate a BrainSphere myelination assay (Figure 1A). Since only a limited number of reference compounds perturbing myelination have been identified as DNT toxicants, an extensive systematic literature review to identify positive and negative test chemicals for assay development was performed.

\section{Results}

\subsection{Selection of Chemicals for Assay Development}

\subsubsection{Literature Review Results}

The literature review search (Table 1) yielded 5223 results in PubMed as of 15 November 2017. Once the PMID list was imported into SWIFT-Review, the program organized articles were sorted in categories based on tags automatically assigned according to predefined search filters for chemicals and topics prepared by information scientists at NIEHS and EPA, as well as on data imported with articles from PubMed, including MeSH terms, supplementary concept records, keywords, publication type, and Medline indexing tags. The majority of studies retrieved in this literature review were tagged as focusing on developmental and neurological outcomes (Figure 1D) and general environmental exposures (Figure 1E).

Once $5 \%$ of articles (262) had been screened based on inclusion and exclusion criteria (Table 2), studies were automatically prioritized in SWIFT-Review, and as expected, more than $90 \%$ of the training set of articles placed within the top $10 \%$ of the ranked list. For the test set of articles, approximately $85 \%$ placed within the top $10 \%$ of the ranked list and nearly all of the test set occurred within the top 25\% of the ranked list (Figure 1F). Given these results, only studies ranked highly $(>0.7 ; 187$ articles) were chosen for further review. Abstract review of these studies was conducted according to inclusion and exclusion criteria (Table 2) and this resulted in the inclusion of 143 studies for full text evaluation. Following a full text review, a list of potential test chemicals was generated, containing nine substances (Figure S1). This list included cuprizone [70], toluene [71], bisphenol A (BPA) [72,73], BDE-99 [74,75], ethanol [76-79], methyl mercury [80], Tris(1,3-dichloro-2propyl) phosphate (TDCPP) [81], vanadium [82-84], and lead [85,86] (Figure 1G). For this study, only four chemicals were selected from this list. 


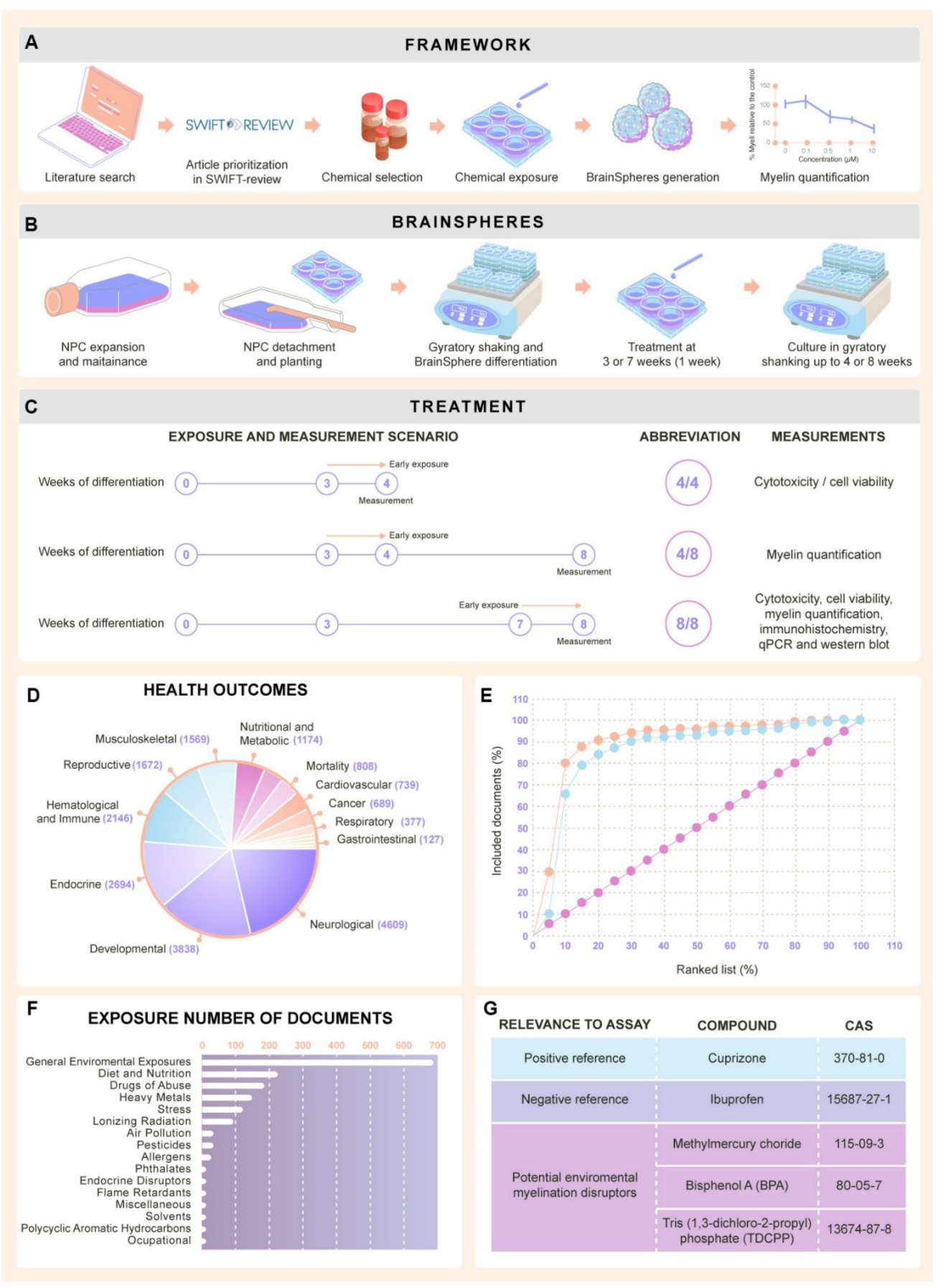

Figure 1. Experimental framework and chemical exposure. (A) Experimental framework for myelin quantification. Literature review was performed to select reference compounds and different exposure scenarios were applied. (B) BrainSphere preparation [61]. NPCs were expanded, transferred to six-well plates, and kept under constant gyratory shaking for eight weeks to form BrainSpheres. (C) Scheme of the three different exposure scenarios used in this study and corresponding abbreviations referenced in text and subsequent figures. (D) Pie graph showing the health outcomes repartition of the articles tagged during the SWIFT-Review. (E) Ranking performance of the prioritization algorithm in SWIFT-Review based on the publications excluded and included in the training set and included in the test set. The orange line shows the percentage of included documents in the training set as they occur in the ranked list and the blue line shows the percentage of included documents in the test set. The pink line shows the baseline performance if the ranking score had been generated arbitrarily. (F) Overview of topics represented in retrieved literature. (G) List of chemicals selected for the DNT study. Non-parametric Kruskal-Wallis test was used to determine significant differences between the different conditions. 
Table 1. Search query for PubMed database.

\begin{tabular}{|c|c|c|c|c|c|}
\hline String & $\begin{array}{l}\text { Combined } \\
\text { with OR }\end{array}$ & & $\begin{array}{c}\text { Combined } \\
\text { with OR }\end{array}$ & & $\begin{array}{l}\text { Combined } \\
\text { with OR }\end{array}$ \\
\hline 1 & $\begin{array}{c}\text { Embryonic and fetal } \\
\text { development, } \\
\text { embryonic structures, } \\
\text { embryonic, embryo, } \\
\text { embryos, embryology, } \\
\text { fetal, fetus, pregnancy, } \\
\text { gestation, gestational, in } \\
\text { utero, prenatal neonatal, } \\
\text { neonate, perinatal, } \\
\text { postnatal, infant, } \\
\text { adolescent, child, fetal } \\
\text { brain, human } \\
\text { development, } \\
\text { developing brain, } \\
\text { neurodevelopmental, } \\
\text { neurodevelopment }\end{array}$ & AND & $\begin{array}{l}\text { Pharmacological and } \\
\text { toxicological } \\
\text { phenomena and } \\
\text { processes, toxicology, } \\
\text { toxicity, toxicity tests, } \\
\text { toxicant, toxicants, toxin, } \\
\text { toxins, toxic actions, } \\
\text { neurotoxicant, } \\
\text { neurotoxicants, } \\
\text { neurotoxin, neurotoxins, } \\
\text { neurotoxins, } \\
\text { pharmacology, } \\
\text { pharmacologic actions, } \\
\text { specialty uses of } \\
\text { chemicals, organic } \\
\text { chemicals, inorganic } \\
\text { chemicals, environment } \\
\text { and public health, } \\
\text { exposure, exposures, } \\
\text { environmental chemical, } \\
\text { environmental } \\
\text { chemicals, } \\
\text { environmental health, } \\
\text { hazard, hazards, } \\
\text { hazardous, xenobiotics }\end{array}$ & \multirow[t]{2}{*}{ AND } & \multirow[t]{2}{*}{$\begin{array}{c}\text { Myelin, oligodendroglia, } \\
\text { myelin sheath, } \\
\text { myelinogenesis, } \\
\text { myelination, myelin } \\
\text { proteins, } \\
\text { oligodendrocyte, } \\
\text { oligodendrocytes, } \\
\text { oligodendrogenesis, } \\
\text { white matter, } \\
\text { dysmyelination, } \\
\text { dysmyelinating, } \\
\text { demyelination, } \\
\text { demyelinating }\end{array}$} \\
\hline 2 & $\begin{array}{r}\text { Developmental neurot } \\
\text { developmental neu } \\
\text { developmental neurc } \\
\text { neurodevelopmental disc } \\
\text { teratoge }\end{array}$ & $\begin{array}{l}\text { nt, des } \\
\text { in, de } \\
\text { ity, ne } \\
\text { prena } \\
\text { atogen }\end{array}$ & $\begin{array}{l}\text { nental neurotoxicants, } \\
\text { nental neurotoxin, } \\
\text { velopmental toxicity, } \\
\text { uries, maternal exposure, } \\
\text { togenic }\end{array}$ & & \\
\hline
\end{tabular}

Table 2. Inclusion and exclusion criteria for study selection.

\begin{tabular}{|c|c|}
\hline Inclusion Criteria & Exclusion Criteria \\
\hline $\begin{array}{l}\text { DNT is investigated with appropriate exposure scenarios (e.g., prenatal } \\
\text { maternal, infant, or childhood exposure (in vivo), exposure during cell } \\
\text { proliferation, differentiation, migration, myelination, or synaptogenesis } \\
\text { (in vitro)) }\end{array}$ & DNT is not investigated \\
\hline $\begin{array}{c}\text { A single chemical exposure is reported with a clearly identified } \\
\text { chemical name or CAS number, or a chemical mixture is reported with } \\
\text { human relevance }\end{array}$ & $\begin{array}{l}\text { A chemical exposure is not reported, a mixture of chemicals is reported } \\
\text { without human relevance, chemicals are not clearly identified, or } \\
\text { exposures are psychosocial (e.g., stress or socioeconomic status), } \\
\text { physical (e.g., radiation, particulate matter, or nanomaterials), or } \\
\text { intrinsic biological traits (e.g., genetic mutations) }\end{array}$ \\
\hline $\begin{array}{l}\text { At least two dose or concentration levels are tested or a single dose is } \\
\text { tested but was chosen based on previous experience with multiple } \\
\text { doses or on human exposure levels }\end{array}$ & $\begin{array}{l}\text { One dose or concentration is tested but was not chosen based on } \\
\text { previous experience with multiple doses or on human exposure levels }\end{array}$ \\
\hline $\begin{array}{c}\text { DNT was evident at doses or concentrations lower than those which } \\
\text { cause maternal toxicity (in vivo), general toxicity (in vivo), or } \\
\text { cytotoxicity (in vitro) }\end{array}$ & $\begin{array}{l}\text { The relationship between DNT and other forms of toxicity were not } \\
\text { described or DNT was only evident at doses that also caused maternal } \\
\text { toxicity (in vivo), general toxicity (in vivo), or cytotoxicity (in vitro) }\end{array}$ \\
\hline $\begin{array}{l}\text { A chemical was characterized as a developmental neurotoxicant using } \\
\text { endpoints associated with myelination in the central nervous system } \\
\text { (e.g., markers or levels of oligodendrocyte differentiation or MBP gene } \\
\text { expression), or a chemical was tested using endpoints associated with } \\
\text { myelination during neurodevelopment but found to have no effect }\end{array}$ & $\begin{array}{c}\text { A chemical was not characterized as a developmental neurotoxicant or } \\
\text { was characterized using endpoints not associated with myelination, or } \\
\text { only with peripheral nervous system myelination }\end{array}$ \\
\hline $\begin{array}{c}\text { Studies with appropriate negative and solvent controls or } \\
\text { control groups }\end{array}$ & $\begin{array}{l}\text { Studies without appropriate negative and solvent controls or } \\
\text { control groups }\end{array}$ \\
\hline
\end{tabular}




\subsubsection{Selection of Test Chemicals from Literature Review}

We selected cuprizone, a copper chelator, as a positive reference compound for myelin assay development for its known ability to induce demyelination and oligodendrocytespecific cell death if exposure continued [87]. Cuprizone is extensively used as a standard demyelinating agent in animal studies of multiple sclerosis [88,89]. In addition, three environmental chemicals, potentially able to disrupt myelin, were selected from the literature review. Methyl mercury is a well-known DNT compound and three studies found in the literature review identified it as a disruptor of myelination during neurodevelopment. Furthermore, perinatal exposure to methyl mercury was found to reduce the oligodendrocyte cell population and alter MBP gene expression in the developing rat cerebellum [80]. Another selected chemical—one of the most common flame retardants, TDCPP—is progressively replacing polybrominated diphenyl ethers (PBDEs). Recently, high concentrations of TDCPP were detected in polyurethane foam in furniture and house dust in the U.S. at levels that matched previous levels of PBDEs [90]. TDCPP has also recently been found to be neurotoxic and to alter neural differentiation in vitro [91]. In addition, it has been demonstrated to modify MBP mRNA and protein expression in zebrafish larvae, possibly acting through thyroid hormone disruption [81]. The third environmental compound, BPA, is an endocrine disruptor with estrogenic activity that is found in many consumer products. It has been shown to impair myelination in rat brain hippocampus development [72] as well as to reduce the population of oligodendrocytes in the rat hippocampus [73].

Finally, ibuprofen, a non-steroidal anti-inflammatory drug (NSAID), was selected as a negative reference compound for assay development, based on the recommendations given in a recent review on reference compounds for alternative DNT test methods [92]. This is a particularly relevant compound for our study as it crosses the BBB [93], has not been demonstrated to elicit DNT, and is a drug accepted during pregnancy and for children [92]. Ibuprofen has also been used as a negative reference compound in a recent in vitro toxicity study on neural cells derived from human embryonic stem cells [94].

This review represents a first step in the effort to identify reference compounds to study perturbation of the myelination process in vitro during brain development. The chemicals for this study were selected to represent various chemical classes and mechanisms of action to demonstrate the robustness and versatility of the BrainSphere model for DNT testing.

\subsection{Maturation of Oligodendrocyte and Expression of Myelin-Related Markers during BrainSphere Differentiation}

To characterize glial maturation in the BrainSpheres, expression of oligodendrocyte-, myelin-, and astrocyte-specific genes was assessed at two, four, and eight weeks of differentiation and compared to the expression found in NPCs. NG2 gene expression, a marker of oligodendrocyte precursors [95], was significantly decreased in BrainSpheres compared to NPCs (Figure 2B). The mRNA levels of both oligodendrocyte progenitor markers OLIG1 and OLIG2 were significantly increased, as BrainSpheres differentiated (Figure 2B), whereas CNP expression did not show any significant changes. SOX10 expression slightly decreased at two and four weeks of differentiation and further increased at eight weeks, but this upregulation was not statistically significant (Figure 2B). The mRNA levels of the myelin-specific markers PLP1, MBP and MOG increased with time in culture, but this was significant only for PLP1 (Figure 2B). Altogether, these gene expression patterns correspond to oligodendrocyte maturation. The results of qRT-PCR were confirmed by immunostainings. The oligodendrocyte marker sulfatide $\mathrm{O} 4$ and myelin markers MBP and PLP1 were evaluated in BrainSphere differentiation at two, four, and eight weeks. MBP presented a very low expression at two weeks, being stronger at four weeks and eight weeks (Figure 2C). The quantification of MBP pixels showed a strong increase between Week 4 and Week 8 (Figure 2D), indicating maturation of myelin starts after four weeks in culture. PLP1, on the contrary, was only expressed at the eight-week time point (Figure 2G). 
A
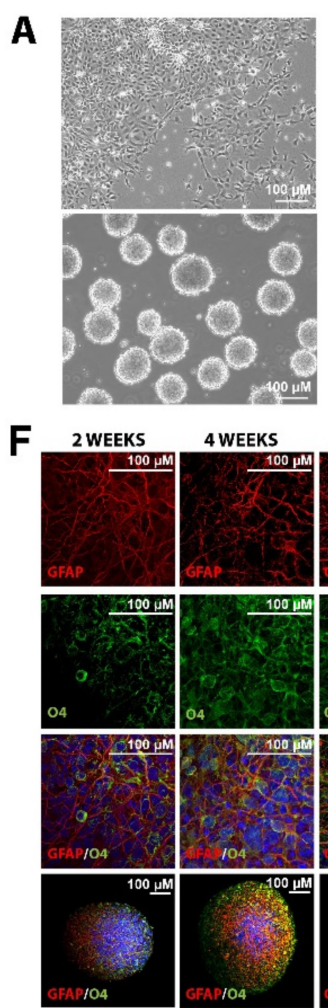

B
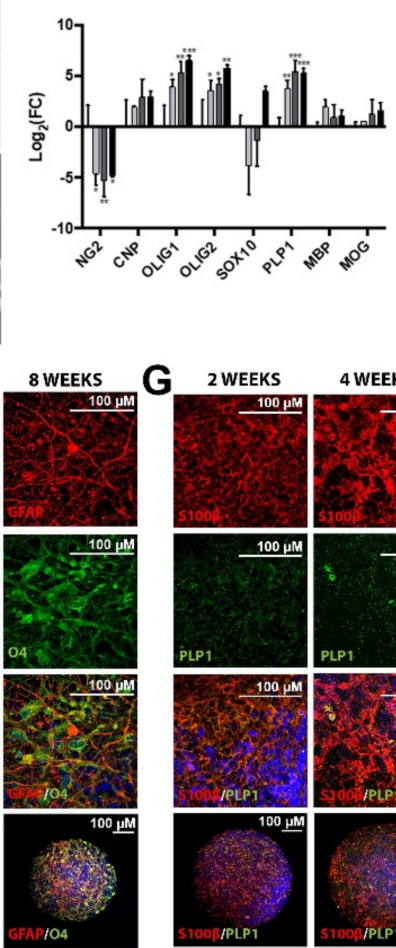
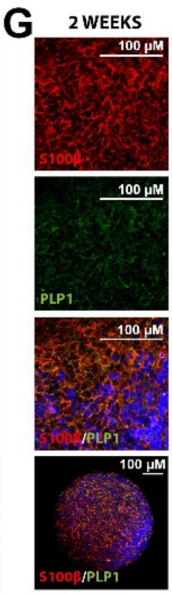

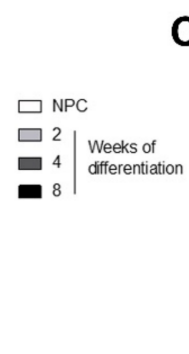

C
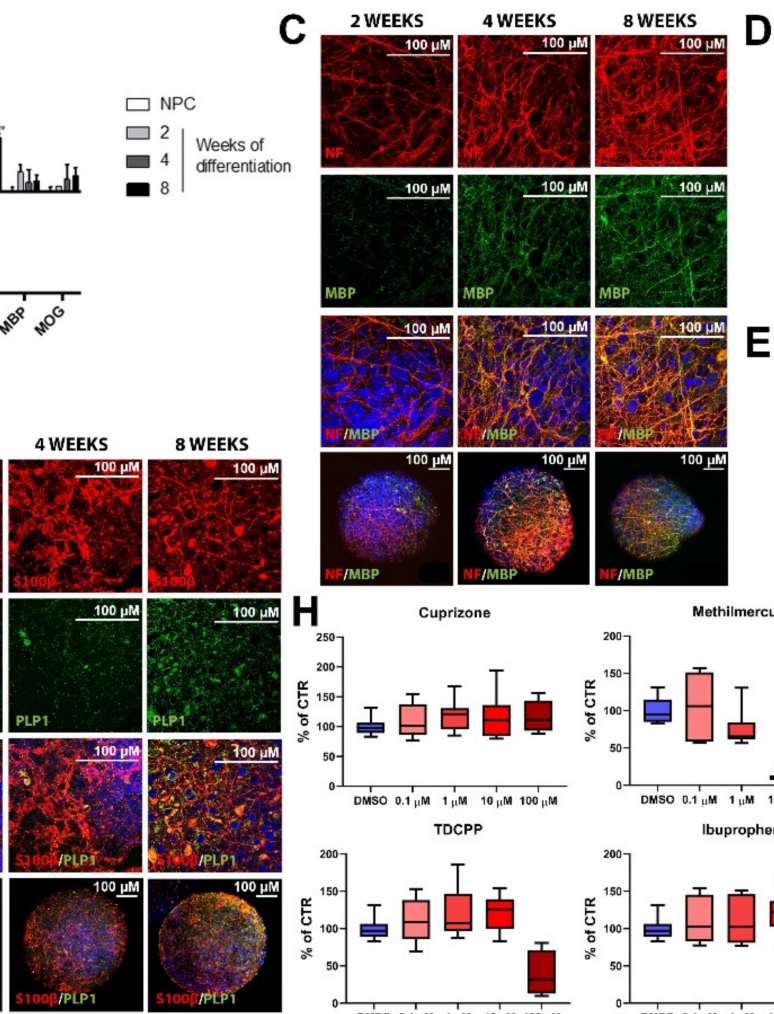

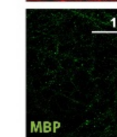

$$
\text { . }
$$
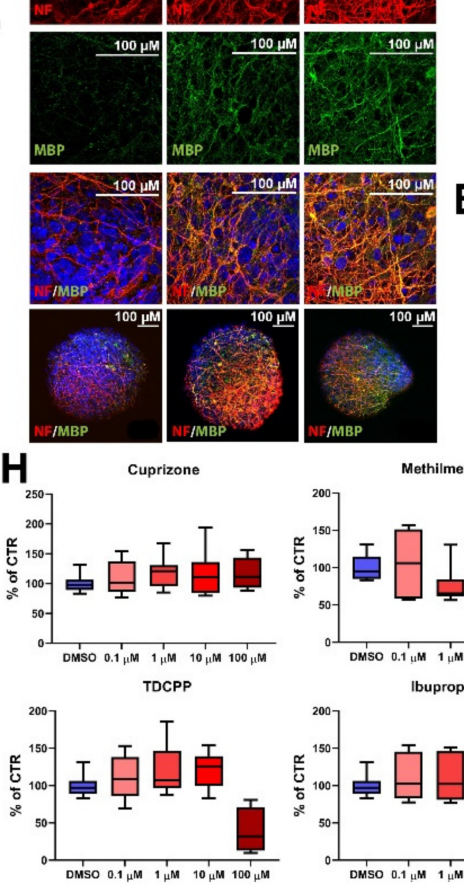

D

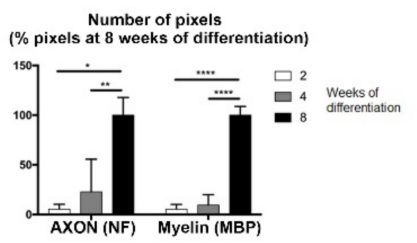

$E$
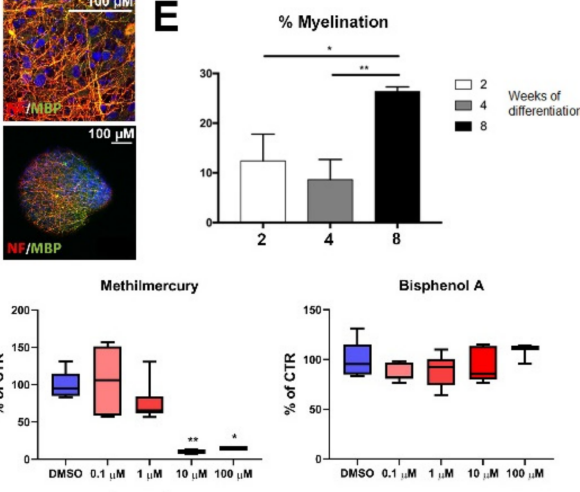

Ibuprophen

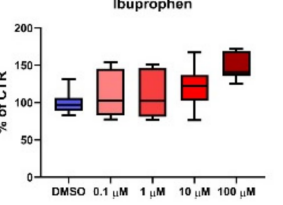

Figure 2. Characterization of glial population in BrainSpheres. (A) Representative bright field images of NPCs (upper panel) and BrainSpheres (lower panel). (B) Development-dependent oligodendrocyte gene expression in BrainSphere (two, four, eight weeks of differentiation compared to baseline expression in NPCs). Gene expression was normalized to GAPDH. (C) Representative confocal images of MBP (myelin marker, green) and NF (axonal marker, red) expression over BrainSpheres differentiation process. (D) Number of pixels on confocal images of axonal marker (NF) and myelin marker (MBP) at two, four and eight weeks of BrainSpheres differentiation (mean $\pm \mathrm{SD}, n=10$ ). (E) Myelination in BrainSpheres (\% of myelinated axons) calculated using CEM plugin at two, four and eight weeks of differentiation. (F) Developmental-dependent GFAP (astrocyte marker, red) and O4 (oligodendrocyte marker, green) protein expression. (G) Development-dependent S100ß (astrocytes marker, red) and PLP1 (myelin marker, green) protein expression. (H) Cell viability measured after a seven-day chemical exposure in the eighth week of differentiation (8/8) by resazurin test. Data are expressed as percentage of vehicle (DMSO) control and displayed as mean \pm SD. $n=6-8$ samples coming from two independent experiments. Non-parametric Kruskal-Wallis test was used to determine significant differences between NPCs and BrainSpheres $\left({ }^{*} p \leq 0.05 ;{ }^{* *} p \leq 0.01 ; * * * p \leq 0.001 ;{ }^{* * * *} p \leq 0.0001\right)$. Scale bars $=100 \mu \mathrm{m}$.

In the case of oligodendrocytes, it was observed that the number of O4-positive cells increases from two to four weeks, showing higher maturation at eight weeks of differentiation (Figure 2F). The staining at eight weeks is also more notable, and $\mathrm{O} 4$ positive cells also appear to have more processes, which is characteristic of mature oligodendrocytes (Figure 2F). These results suggest the presence of fewer but more mature oligodendrocytes, indicating a continuing maturation process.

Furthermore, the continuing maturation of neurons is observed by the increasing number of pixels of the NF200 immunostaining with time in culture (Figure 2C-E), and for astrocytes by the increase in GFAP and S100 $\beta$ immunofluorescence (Figure 2F,G).

\subsection{Exposure to DNT Selected Compounds Alter Myelin in BrainSpheres}

\subsubsection{Cytotoxicity Assessment of Test Chemicals}

BrainSpheres were exposed to a range of concentrations $(0.1-100 \mu \mathrm{M})$ of the test compounds for seven days. Samples were collected on Day 7 of exposure and cytotoxicity was determined using the resazurin assay. Cuprizone, BPA, and ibuprofen did not induce any change in BrainSpheres viability at the tested concentrations (Figure 2H). 
Methylmercury chloride was found cytotoxic at 10 during the latest stage of differentiation (Figure 2H). At $4 / 4$ none of the concentrations showed statistically significant cytotoxicity (data not shown).

\subsubsection{Myelin Is Affected after Exposure of BrainSpheres to Chemicals Inducing DNT}

MBP expression was quantified in confocal images of BrainSpheres after exposure to the test chemicals following the treatment schemes $4 / 8$ and $8 / 8$ (Figure 1C). No changes in myelin were observed in $4 / 8$ exposure to any of the compounds (data not shown). Briefly, confocal images were converted in binary images (Figure 3A) and then NF200 (axonal) pixels and MBP (myelin) pixels were overlapped and quantified using Kerman protocol [57]. A significant decrease in the percentage of BrainSphere myelination was observed when exposed to all test chemicals during the eighth week of differentiation $(8 / 8)$, except for ibuprofen (Figure 3B,C). A concentration-dependent decrease in myelination was observed after exposure to positive reference compound cuprizone (Figure 3C). Exposure to methyl mercury chloride resulted in a significant decrease in myelination only at $10 \mu \mathrm{M}$ (Figure 3C), which was a cytotoxic concentration $(8 / 8$; Figure $2 \mathrm{H})$. Although quantification did not allow to observe statistically significant effects at lower concentrations, immunohistochemistry showed a slight decrease in MBP staining at $1 \mu \mathrm{M}$ (Figure 3B). Exposure to BPA and TDCPP resulted in significantly, although not concentration-dependent, reduced myelination at all concentrations tested (Figure 3B,C). It is important to note that these changes in myelination were observed in the absence of changes in NF200 immunostaining. No significant difference was detected in BrainSpheres treated with ibuprofen compared to the DMSO control (Figure 3B,C). In addition, no decrease in the percentage of myelination was observed at eight weeks of differentiation when exposure to test chemicals occurred during the fourth week of differentiation and cultures were allowed to recover for four weeks (data no shown).

Since PLP1 presented a very different distribution than MBP (Figure 4A), it was not possible to use overlapping of its staining with NF staining, as for MBP [57]. Instead, we quantified PLP1 total fluorescence (Figure 4B) using the ImageJ plugin and we performed Western blot (Figure 4C,D). Exposure to non-cytotoxic concentrations of cuprizone $(1,10$ and $50 \mu \mathrm{M})$, methyl mercury $(0.5,1$ and $10 \mu \mathrm{M})$, BPA $(50$ and $100 \mu \mathrm{M})$ and TDCPP $(0.5,1,10$ and $50 \mu \mathrm{M}$ ) led to statistically significant reduction of PLP1 in total fluorescence (Figure 4B). Western blot quantification (Figure 4C,D) of PLP1 showed a statistically significant decrease after exposure to methylmercury and TDCPP, however, most of the chemicals (with the exception of ibuprofen) showed a clear down-regulation tendency.

\section{Discussion}

Most human in vitro brain models are not suited to study myelination/demyelination processes, as they do not provide the proper 3D and multicellular CNS microenvironment. Here, we present an iPSC-derived model to study human myelin that includes the main CNS cell phenotypes [61]. BrainSpheres constitute a reproducible human brain model able to recapitulate some of the key events of neurodevelopment, such as proliferation, differentiation of glial cells and neurons, neurite outgrowth, and synaptogenesis [69]. Furthermore, myelination was previously shown to increase progressively with time in culture [61] indicating the usefulness of the model to study this developmental process, in particular since electron microscopy revealed a high level of compaction of myelin sheath around the axons [61]. The gene expression patterns reported in the present study are in line with the ongoing oligodendrocyte maturation and myelination previously observed [61]. In this study, we have established a strategy (myelin quantification, PLP1 total fluorescence quantification and Western blot) to scrutinize myelin. We propose this strategy to investigate demyelinating diseases and to detect potential NT and DNT compounds. As proof of principle, we have used positive and negative reference chemicals as well as known DNT chemicals to test the capability of the model to identify and quantify in a concentration-response relationship potential myelin disruptor compounds. 
A
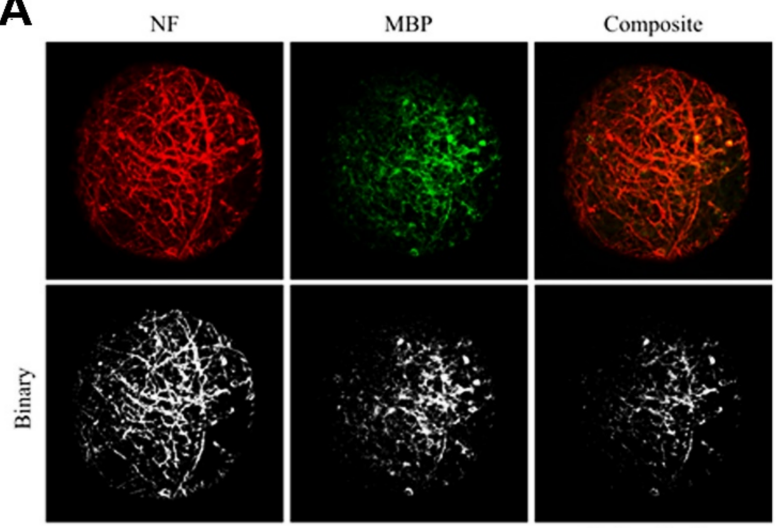

Co-localization
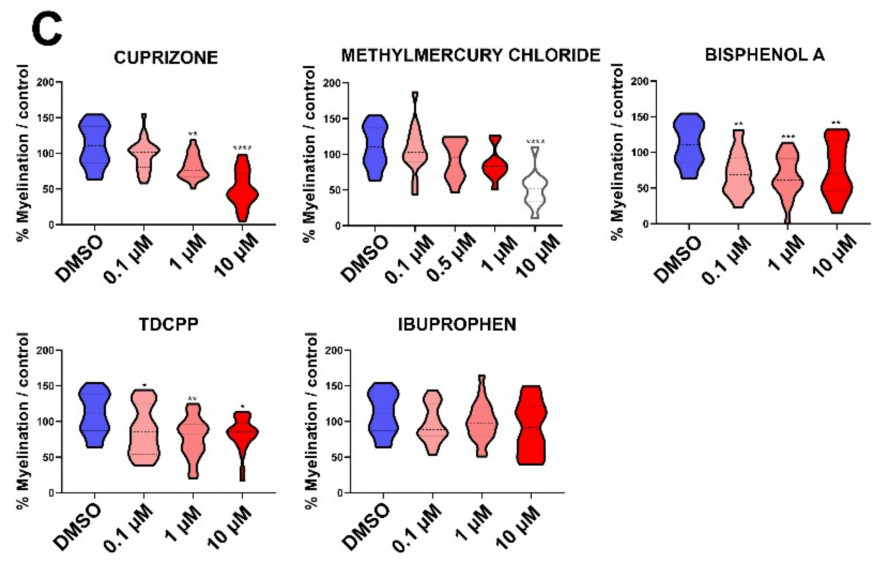

B
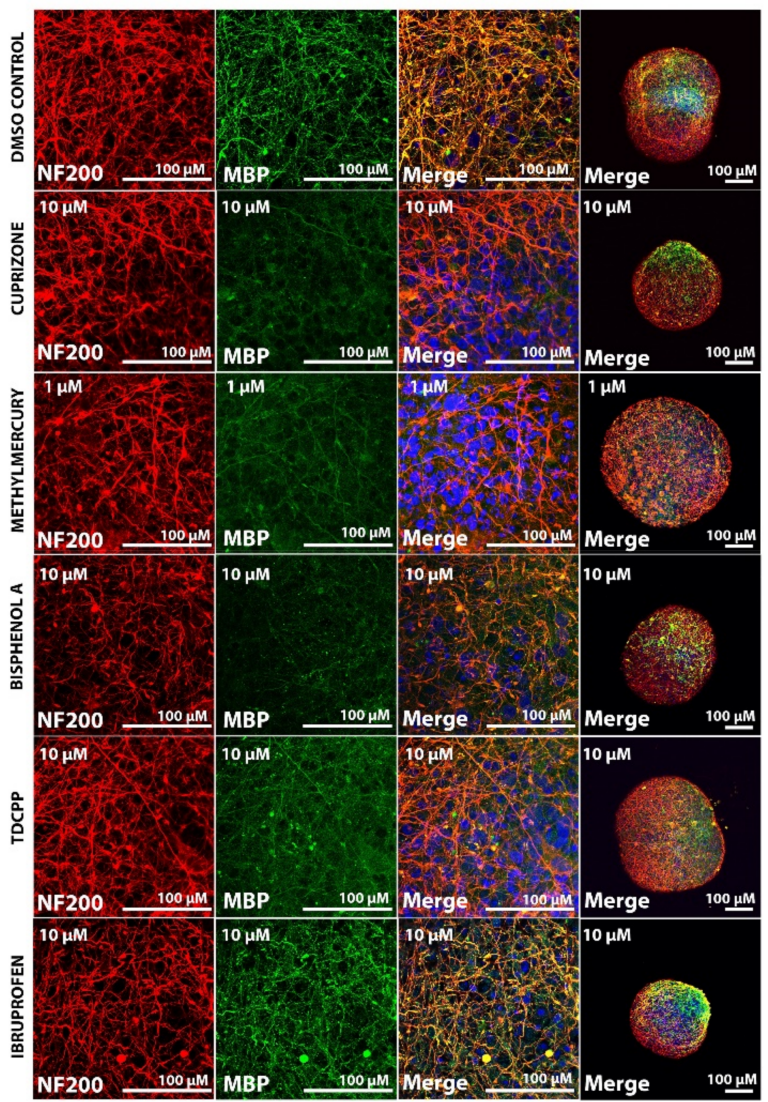

Figure 3. Chemical exposure altered myelin in BrainSpheres. (A) Example of binary conversion of confocal images using CEM plugin. (B) Confocal images of representative BrainSpheres exposed to the highest non-cytotoxic concentration of each chemical. Treatment, concentration, and antibody used are indicated in each picture. White bars correspond to $50 \mu \mathrm{m}$. (C) Quantification of BrainSpheres myelination after chemical exposure. Percentage of myelination was quantified as co-localization of MBP and NF immunocytochemical staining in confocal images of BrainSpheres taken at the end of the eighth week of differentiation following a seven-day exposure to test chemicals during eighth (8/8) week. The percentage of myelination was normalized to the mean percentage of myelination in the vehicle (DMSO) control samples. Each bar in the 8/8 experiment represents pooled results from three experiments (first experiment $n=5$, second experiment $n=10$, third experiment $n=5$ total $n=20$ BrainSpheres). Kruskal-Wallis no-parametric test was used to determine significant differences between control and exposed samples ${ }^{*} p \leq 0.05 ;{ }^{* *} p \leq 0.01 ;{ }^{* * *} p \leq 0.001 ;{ }^{* * * *} p \leq 0.0001$ ). We also performed total quantification of PLP1, another myelin marker. 
A

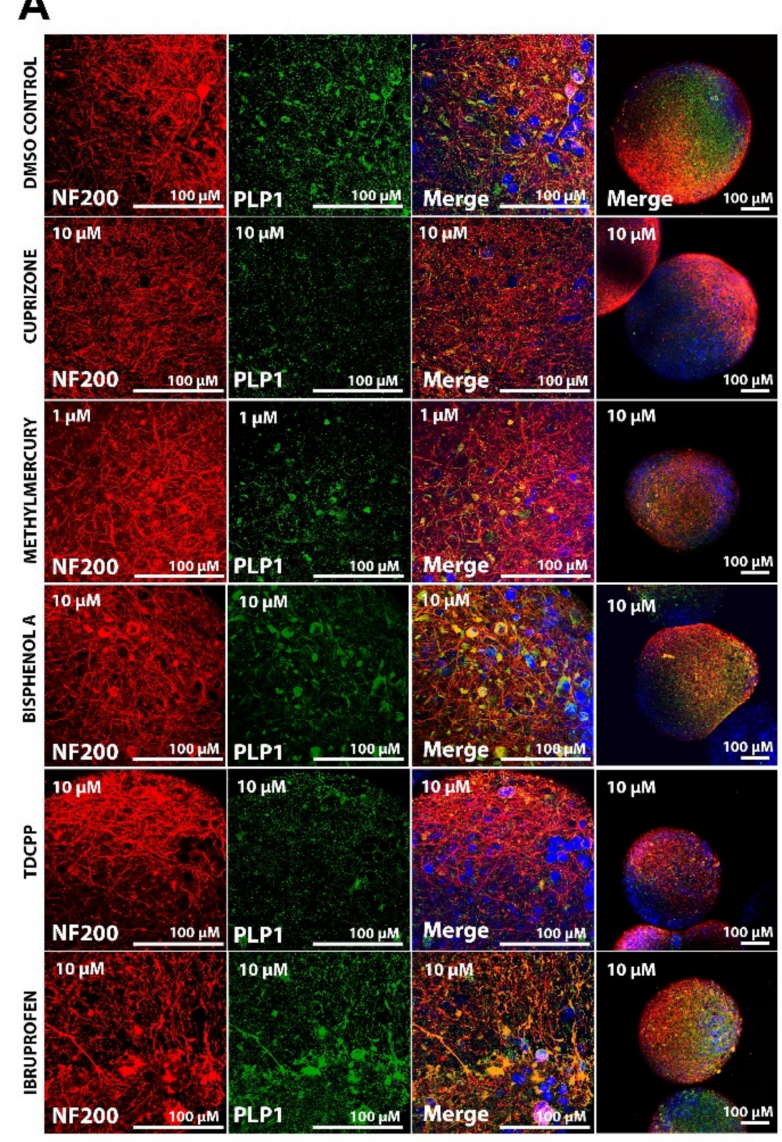

\section{B}

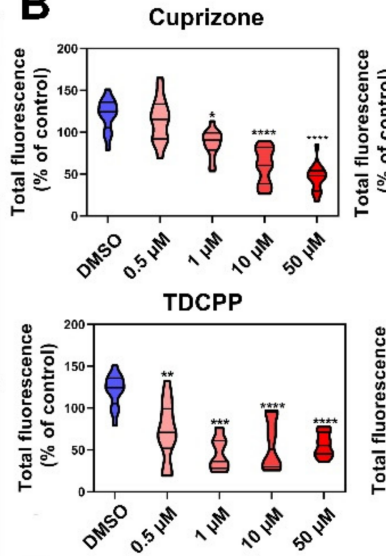

C

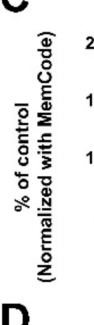

Western blot quantification
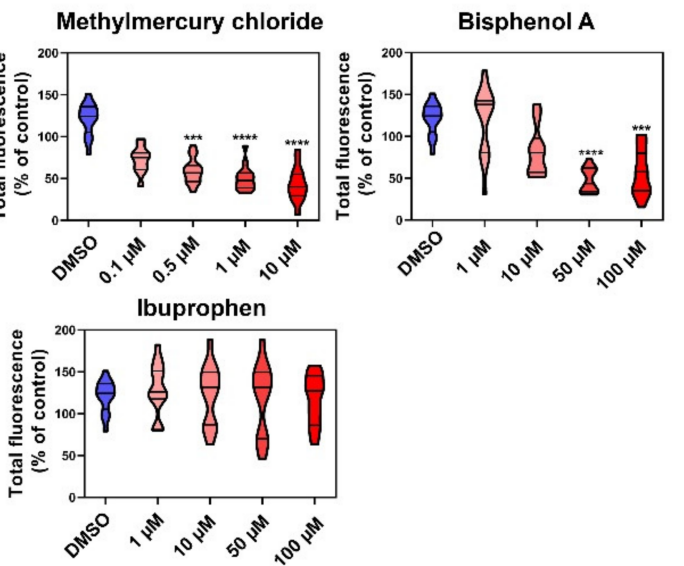

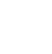

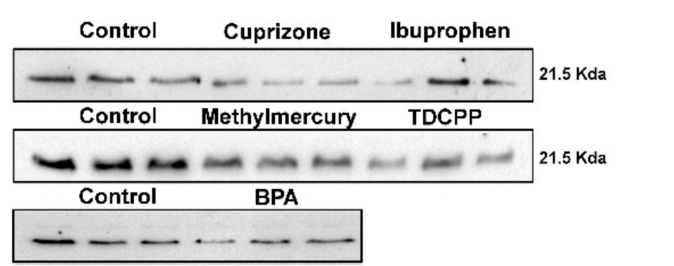

ㅁontrol

ㅁ Cuprizone $10 \mu \mathrm{M}$

ㅁ Methylmercury $1 \mu \mathrm{M}$

口 TDCPP $10 \mu \mathrm{M}$

$\square$ BPA $10 \mu \mathrm{M}$

口 Ibuprophen $10 \mu \mathrm{M}$

Figure 4. Chemical exposure altered proteolipid protein 1 in BrainSpheres. (A) Confocal images of a representative BrainSphere exposed to the highest non-cytotoxic concentration of each chemical. Treatment, concentration, and antibody used are indicated in each picture. White bars correspond to $50 \mu \mathrm{m}$. (B) PLP1 total fluorescence quantification in percentage of the control. Total fluorescence was measured with ImageJ for PLP1 immunocytochemical staining in confocal images of BrainSpheres taken at the end of the eighth week of differentiation following a seven-day exposure to test chemicals during the eighth $(8 / 8)$ week. The percentage of PLP1 was normalized to the mean percentage of the vehicle (DMSO) control samples. Each value represents pooled results of two independent experiments with 6 separate BrainSpheres per experiment $(n=12)$. Error bars represent standard deviation. (C) Western blot quantification $(n=3$ per experiment, 2 independent experiments) of PLP1 protein. Samples were normalized with MemCode. (D) Representative Western blots Kruskal-Wallis no-parametric test was used to determine significant differences between control and exposed samples $\left({ }^{*} p \leq 0.05 ;{ }^{* *} p \leq 0.01 ;{ }^{* * *} p \leq 0.001 ;{ }^{* * *} p \leq 0.0001\right)$.

To evaluate the use of the BrainSphere model as a myelination test system for DNT evaluation and for disease modelling, we first selected test chemicals with the potential to disrupt oligodendrocytes or myelination (as based on a literature review). Test chemicals, as defined by the ECVAM Biostatistics Task Force in its recommendations for development of alternative toxicological methods, are a set of chemicals of different chemical classes that have been shown to affect the desired endpoint in vivo [96]. In this literature review, in vitro data were also considered due to the possibility that in vivo information would not be available for many chemicals with potential to disrupt oligodendrocytes or myelination.

The myelin quantification assay developed by Kerman and collaborators [57], and a posteriori adapted to BrainSpheres model [61], showed myelination disruption after one week of treatment with cuprizone, but not after the exposure to the negative control compound ibuprofen, emphasizing the ability of this strategy to specifically detect demyelinating chemical agents. Demyelination was also observed after exposure to BPA and TDCPP (Figure 3C) at non-cytotoxic concentrations, reinforcing the previous reports 
about their potential to induce myelin disruption $[72,73,76]$ and DNT. Methyl mercury chloride significantly decreased myelination only at concentrations reducing cell viability, precluding the identification of methyl mercury as a specific myelin disruptor (Figure 2H). However, this effect may have been missed due to the intervals of concentrations used and the timepoints of assessment.

The effects on myelination were only observed after the exposure to chemicals during the latest window of differentiation of BrainSpheres (Figures 1C and 3C), suggesting that these chemicals target only more mature, deposited myelin and/or that the myelin quantification assay is not sensitive enough to identify very subtly disrupted or malformed myelin - and therefore, may not capture the full effect of the test chemicals on early oligodendrocyte differentiation. For example, decrease in myelination would not be detected in this assessment in case of a simultaneous axonal loss, since the percentage of myelination is relative to the axons in the system. However, this is an advantage of the assay since it is meant to elucidate specific deleterious effects on myelination. We believe that other DNT compounds may also be able to produce effects in early stages of differentiation, so examination of early stage exposure will be important for future DNT evaluation.

Total fluorescence of PLP1 was also a good way to measure the disruption of myelin by the test chemicals (Figure 4B). PLP1 quantification showed similar results as the quantification of myelination. Indeed, all the chemicals (except ibuprofen) reduced PLP1 content. The variation on the sensitivity of the methods used for MBP and PLP1 quantification, might be due to the detection method rather than the mechanism of action of the different compounds. We consider that the combination of all these methods could decrease uncertainties in the screening of potentially toxic compounds, and help compounds safety assessment.

As a myelin study complement, we studied the effect of tested chemicals on oligodendrocytes and astrocytes population, although confocal image analyses were difficult to assess. The morphology and number of $\mathrm{O} 4$ positive cells are quite variable between different sections of the same BrainSpheres (Figure S4). Nevertheless, in the confocal images, we observed a decrease of the cell body size of the $\mathrm{O} 4$ positive cells (Figure $\mathrm{S} 4$ ) after cuprizone and TDCPP treatment. TDCPP also showed some morphology changes at the higher concentration $(50 \mu \mathrm{M})$ for $\mathrm{S} 100 \beta$ marker, showing thicker cell bodies. It is also possible to observe that after the exposure to 1 and $10 \mu \mathrm{M}$ of methyl mercury and the O4-positive cells phenotype is lost, indicating a possible effect on the viability of the oligodendrocytes present (Figure S4) In addition, the $10 \mu \mathrm{M}$ concentration of methyl mercury was able to produce some general cytotoxic effects as well.

A few limitations of this study should be stated: The experimental design employed only one cell line. Testing several lines with different genetic backgrounds would add human genetic variability to the test, increasing its robustness. A larger list of chemicals and higher number of experimental replicates will be required to further validate the model. Finally, although this study has been mainly focused on chemical evaluation, we believe that the model could also be used to study diseases related to myelin disruption.

Overall, the results from this study demonstrate that the BrainSphere is a promising model for myelination/demyelination studies using different quantification methods. This study has also provided preliminary data for future performance assessment of the BrainSpheres as a relevant model for DNT testing. Further work is needed to improve the throughput of this assay in BrainSpheres to be able to test more chemicals.

\section{Materials and Methods}

\subsection{Literature Review to Identify Test Chemicals}

A comprehensive literature review was conducted to retrieve studies on exposures to environmental compounds targeting myelination in the CNS during development, with the aim of selecting test chemicals to assess the performance of our endpoints for the myelin assay. 
Search strings (Table 1) were combined with the Boolean operator OR and the asterisk $\left.{ }^{*}\right)$ was used as a wildcard in the search. The term: "NOT (("peripheral" [tw]) NOT ("central" [tw])) NOT (("peripheral nervous system" [mesh]) NOT ("central nervous system" [mesh])) NOT (review [pt]) NOT ("review" [tw]) NOT ("systematic" [sb]) NOT (case reports [pt]) NOT (comment [pt]) NOT (congresses [pt]) AND (English [lang])" was added to the end of the combined search strings to exclude studies exclusively to the peripheral system, exclude review articles, case reports, comments, and congresses, and only include articles in the English language.

\section{Study Prioritization and Selection}

The PubMed ID (PMID) list of retrieved articles was exported from PubMed and imported into Sciome Workbench for Interactive Computer-Facilitated Text-mining (SWIFT)Review software (Desktop Version 1.21, Sciome LLC, Durham, NC, USA), which is a freely available software that can be used in literature prioritization. Within SWIFT-Review, the title and abstract of $5 \%$ (262 papers) of the retrieved results were manually screened and annotated as "included" or "excluded" based on predetermined inclusion and exclusion criteria (Table 2). These articles were marked as "training items" within the program. In addition to the $5 \%$ of articles used to train the machine learning algorithm within SWIFT-Review, another 5\% of articles were annotated as "included" but not marked as "training items" to serve as the test-set. The "Prioritize" tool was then used to automatically triage the complete set of articles, and a prioritization score ranging from zero to one was computed for each article by the program, such that the articles similar to the "included" articles marked as "training items" and ranked near the top of the list, and the articles similar to the "excluded" articles are ranked near the bottom. A report of the ranking performance of the algorithm was then generated in SWIFT-Review.

Then, a threshold ranking was selected for abstract and title review within the SWIFTReview program based on the inclusion and exclusion criteria in Table 2. To generate a list of possible test chemicals (Table S2), full text review was then conducted on articles included from the title and abstract review process. Test chemicals for assay development were then selected (Figure 1G) based on proposed mechanisms of myelin disruption in the included studies (Figure S2).

\subsection{Generation of Neural Progenitor Cells from Human Induced Pluripotent Stem Cells}

Neural progenitor cells (NPCs) were generated from induced pluripotent stem cells (iPSCs) derived from human CCD-1079Sk fibroblasts (ATCC ${ }^{\circledR}$ CRL-2097) using EpsteinBarr virus-based vectors and embryoid body formation as previously described [97,98] (Figure 2A: NPCs were then plated in $175 \mathrm{~cm}^{2}$ Nunc $^{\mathrm{TM}}$ EasYFlask ${ }^{\mathrm{TM}}$ Cell Culture Flasks (Thermo Fisher, Waltham, MA, USA) coated with poly-L-ornithine (PLO, Sigma-Aldrich, ST. Louis, MO, USA) and laminin from Engelbreth-Holm-Swarm murine sarcoma basement membrane (Sigma-Aldrich) in NPC medium (StemPro ${ }^{\circledR}$ serum-free human neural stem cell culture medium, NSC SFM, GIBCO) containing KnockOut ${ }^{\mathrm{TM}}$ D-MEM/F-12 basal medium (GIBCO, Waltham, MA, USA) supplemented with $1 \%$ StemPro ${ }^{\circledR}$ NSC SFM supplement (GIBCO), 1\% penicillin streptomycin glutamine (GIBCO), 1\% Glutamax (GIBCO), $0.01 \mu \mathrm{g} / \mathrm{mL}$ basic fibroblast growth factor (bFGF, GIBCO), and $0.01 \mu \mathrm{g} / \mathrm{mL}$ epidermal growth factor (EGF, GIBCO) [61]). Medium was filtered using a bottle-top filter (Nalgene ${ }^{\circledR}$ Rapid-Flow ${ }^{\mathrm{TM}} 0.2 \mu \mathrm{m}, 500 \mathrm{~mL}$, Thermo Fisher) prior to the addition of growth factors [61]. NPC cultures were maintained at $37^{\circ} \mathrm{C}$ in an atmosphere of $5 \% \mathrm{CO}_{2}$ and half of the media was changed daily [61]. For their expansion, NPCs were detached mechanically with a cell scraper (2-Posit. Blade 25, Sarstedt, Newton, NC, USA) [61]. NPCs were karyotyped (Figure S1) as well as screened and found to be negative for all strains of mycoplasma (Figure S1).

To generate stocks of NPCs (Passages 15-22), cells were detached mechanically through scraping, placed in STEMdiff ${ }^{\mathrm{TM}}$ neural progenitor freezing medium (STEMCELL Technologies, Cambridge, MA, USA), and then transferred to cryopreservation tubes 
(Nalgene ${ }^{\circledR}$ cryogenic vials, 2 mL, Sigma Aldrich, ST. Louis, MO, USA). Tubes were stored in a cell freezing container (Thermo Scientific ${ }^{\mathrm{TM}}$ Mr. Frosty ${ }^{\mathrm{TM}}$ Freezing Container, Thermo Fisher, Waltham, MA, USA) containing isopropanol (Sigma-Aldrich) at $-80{ }^{\circ} \mathrm{C}$ for a minimum of $4 \mathrm{~h}$ and then transferred to liquid nitrogen for long-term storage.

\subsection{Generation of the 3D Human Brain Model (BrainSpheres)}

NPCs were thawed and expanded for 2-3 weeks. BrainSpheres were then prepared as previously reported [61]. Briefly, two million NPCs per well were plated in non-coated 6-well plates in $2 \mathrm{~mL}$ of NPC medium and incubated at $37^{\circ} \mathrm{C}, 5 \% \mathrm{CO}_{2}$ as free-floating cultures under constant gyratory shaking at $88 \mathrm{rpm}$ (Figure 2A). After two days, medium was exchanged to differentiation medium (Neurobasal ${ }^{\circledR}$ electro medium (GIBCO) supplemented with 1\% Penicillin Streptomycin Glutamine (GIBCO), 1\% Glutamax (GIBCO), $1 \% \mathrm{~B}-27^{\circledR}$ Electrophysiology supplement (GIBCO), $0.02 \mu \mathrm{g} / \mathrm{mL}$ human recombinant glialcell derived neurotrophic factor (GDNF, Gemini Bio, West Sacramento, CA, USA), and $0.02 \mu \mathrm{g} / \mathrm{mL}$ human recombinant brain-derived neurotrophic factor (BDNF, Gemini Bio, West Sacramento, CA, USA)). Cultures were maintained for eight weeks at $37^{\circ} \mathrm{C}, 5 \% \mathrm{CO}_{2}$ under constant gyratory shaking at $88 \mathrm{rpm}$, and differentiation medium was changed every second day (Figure 1B).

\subsection{Chemical Exposure}

The BrainSpheres (were exposed to the set of five test chemicals: Cuprizone (Sigma Aldrich, \#14690), Methylmercury chloride (Sigma Aldrich, \#442534), Bisphenol A (BPA; Sigma Aldrich, \#239658), Tris(1,3-dichloro-2-propyl) phosphate (TDCPP; Sigma Aldrich, \#32951), and Ibuprofen (Sigma Aldrich, ST. Louis, MO, USA, \#I4883) at concentrations ranging from $0.1 \mu \mathrm{M}$ to $100 \mu \mathrm{M}$. Stock solutions of the chemicals were prepared in DMSO. BrainSpheres were exposed for seven days in either the fourth or eighth week of differentiation. In the former case, measurements were performed at the end of the treatment week (referred to as 4/4) and after four more post-treatment weeks in absence of any chemical $(4 / 8)$, and, in the latter case, measurements were performed at the end of the exposure $(8 / 8)$ (Figure 1C). Medium containing fresh chemicals or vehicle (DMSO) was changed every $48 \mathrm{~h}$. DMSO final concentration in medium was maintained at $0.1 \%$ [32]. Experiments were performed in two independent laboratories.

\subsection{Cell Viability Assessment}

Cell viability was assessed using the resazurin assay to select subcytotoxic concentrations with potential to disrupt myelination in BrainSpheres without inducing general cytotoxicity. At the end of the exposure (8/8), BrainSpheres were transferred to 24-well plates in $500 \mu \mathrm{L}$ of differentiation medium. Then, $5 \mu \mathrm{L}$ of a $1 \mathrm{mg} / \mathrm{mL}$ resazurin sodium salt (Sigma-Aldrich) stock solution in $1 \times$ PBS was added to each well, and plates were kept on a gyratory shaker at $88 \mathrm{rpm}$ in a humidified incubator at $37^{\circ} \mathrm{C}$ with $5 \% \mathrm{CO}_{2}$. After incubation for three hours, $100 \mu \mathrm{L}$ aliquots of sample medium were transferred to a 96-well plate, and the fluorescence of the resazurin metabolite (resorufin) was measured in a multiwell fluorometric plate reader (Cytofluor Multi-well Plate Reader Series 4000, Perspective Biosystem, Framingham, MA, USA) at $530 \mathrm{~nm} / 590 \mathrm{~nm}$ (excitation/emission). Cell viability was determined for three replicates by normalization of absorbance measurements from the test samples to the vehicle (DMSO) control samples. Blank subtraction was performed with normal media without cells. Two independent experiments with 3 technical replicates were performed. Replicate are defined as independent wells in a 6-well plate.

\subsection{Immunocytochemical Staining and Confocal Imaging}

BrainSpheres were fixed for 30 min with $4 \%$ paraformaldehyde, washed three times with $1 \times$ PBS for $10 \mathrm{~min}$ each, then incubated in blocking solution $(5 \%$ normal goat serum (NGS) and $4 \% 1 \times$ Triton in $1 \times$ PBS) for two hours on a shaker at room temperature. Brain- 
Spheres were then incubated with primary antibodies (Table 3) diluted in PBS containing $5 \%$ NGS and $1 \% 1 \times$ Triton at $4{ }^{\circ} \mathrm{C}$ for $48 \mathrm{~h}$.

Table 3. Primary antibodies.

\begin{tabular}{cccc}
\hline Name & Abbreviation & Brand & Reference \\
\hline Neurofilament 200 & NF & Sigma & N4142 \\
Myelin basic protein & MBP & BioLegend & 808402 \\
Proteolipid protein 1 & PLP1 & Biorad & MCA839G \\
Oligodendrocyte marker 4 & O4 & R\&D systems & MAB1326 \\
Glial fibrillary acidic protein & GFAP * & Sigma & G9269 \\
S100 calcium-binding protein B & S100B * & Abcam & ab52642 \\
\hline
\end{tabular}

* Antibody used for results displayed in Supplementary Material Data.

BrainSpheres were washed with PBS five times for $30 \mathrm{~min}$ each and further incubated for one hour with secondary antibodies (goat anti-mouse Alexa Fluor 488 IgG (Invitrogen) or goat anti-rabbit Alexa fluor 568 IgG (Invitrogen, Waltham, MA, USA), 1:250 in PBS containing $5 \%$ NGS) on a shaker at room temperature. BrainSpheres were then washed with PBS five times for 30 min each, and nuclei were stained with Hoechst 33342 Trihydrochloride Trihydrate (Invitrogen, 1:10,000 in PBS) for $30 \mathrm{~min}$ on a shaker. BrainSpheres were then mounted on glass slides using mounting medium (Immu-Mount, Thermo Scientific, Waltham, MA, USA). Images were taken using a confocal microscope (Zeiss LSM 700 Confocal III and Zeiss LSM 780 GaAsP) and visualized in ZEN Imaging software (Zeiss, Jena, Germany).

\subsection{Myelin Quantification}

BrainSphere myelination was quantified using a protocol adapted from Kerman et al. (2015) [57] for computer-assisted evaluation of myelin formation on ImageJ [57]. Briefly, stacks of confocal images of BrainSpheres that were immunocytochemically stained for NF and MBP were split into single channel images, brightness was adjusted to maximize signal-to-noise ratio, and the images were converted into black and white binary images. Myelination, as defined by the pixels that overlap between the binary single-channel images of oligodendrocytes (MBP staining) and axons (NF staining), was then quantified using the computer-assisted evaluation of myelin formation (CEM) plugin. The output of CEM is percent of myelination, as defined by pixel overlap. At least five images for each condition from at least two independent experiments were analyzed with this protocol. Data are expressed as percent of axons myelinated relative to the vehicle (DMSO) control.

The myelin marker proteolipid protein 1 (PLP1) was evaluated by measuring total fluorescence in ImageJ. To calculate the corrected total cell fluorescence (CTCF) the following formula was used: $\mathrm{CTCF}=$ integrated density-area of selected cell X Mean fluorescence of background readings). Data are expressed as percent of CTCF to the vehicle (DMSO) control.

\subsection{Gene Expression Analysis}

Gene expression analysis was conducted using quantitative reverse transcription PCR (qRT-PCR). Briefly, total RNA was extracted from NPCs and BrainSphere samples at two, four, and eight weeks of differentiation, with Invitrogen TRIzol Reagent (Thermo Fisher) according to the TRIzol Reagent User Guide (Invitrogen, Waltham, MA, USA). RNA quantity and purity were determined using NanoDrop 2000c (Thermo Scientific). One microgram of RNA was reverse-transcribed using M-MLV Promega Reverse Transcriptase (Promega, Madison, WI, USA) according to the manufacturer's recommendations. Gene expression was then evaluated using specific TaqMan ${ }^{\circledR}$ gene expression assays (Table 4; Life Technologies, Carlsbad, CA, USA). Three housekeeping genes were tested ( $\beta$-actin, 18S and glyceraldehyde 3-phosphate dehydrogenase (GAPDH)) and results were normalized to the most stable (in our results, GAPDH). qRT-PCR was performed on a 7500 Fast Real 
Time PCR System machine (Applied Biosystems, Waltham, MA, USA). Each sample was analyzed in triplicates. $\log _{2}$ fold change was calculated for biological triplicates using the $2^{-\Delta \Delta \mathrm{CT}}$ method described by Livak and Schmittgen (2001) [99].

Table 4. TaqMan ${ }^{\circledR}$ gene expression assays.

\begin{tabular}{ccc}
\hline Gene Name & Abbreviation & Taqman $^{\circledR}$ Assay ID \\
\hline Neural-glial antigen 2 (chondroitin sulfate proteoglycan 4) & NG2 (CSPG4) & Hs00361541_g1 \\
Oligodendrocyte transcription factor 1 & OLIG1 Hs00744293_s1 \\
Oligodendrocyte transcription factor 2 & OLIG2 & Hs00300164_s1 \\
SOX-10 transcription factor & SOX10 & Hs00366918_m1 \\
Adenomatous polyposis coli & APC & Hs01568269_m1 \\
Proteolipid protein 1 & PLP1 & Hs00166914_m1 \\
2', $3^{\prime}$-Cyclic-nucleotide 3'-phosphodiesterase & CNP & Hs00263981_m1 \\
Myelin oligodendrocyte glycoprotein & MOG & Hs00921945_m1 1 \\
Myelin basic protein & MBP & Taqman ${ }^{\circledR}$ Assay ID \\
\hline Housekeeping Genes & Abbreviation & Hs01060665_g1 \\
B-actin & ACTB & Hs999999_01 \\
Glyceraldehyde 3-phosphate dehydrogenase & GAPDH & Hs02786624_g1
\end{tabular}

\subsection{Western Blot}

One week after exposure to the different compounds, BrainSpheres were washed with PBS and lysed in RIPA Buffer (R0278, Merck, Kenilworth, NJ, USA) with protease and phosphatase inhibitors (78443, Thermo Fisher). Protein content in the lysates was measured with BCA assay (Pierce BCA Protein Assay Kit, 23225, Thermo Scientific). Proteins $(40 \mu \mathrm{g}$ in $30 \mu \mathrm{L})$ were separated using $15 \%$ acrylamide gel at constant voltage $(120 \mathrm{~V}$, 1h30). After transfer to nitrocellulose membranes (BioRad) for $7 \mathrm{~min}$ at constant voltage (25 V) under semi-dry condition (Transblot SD semi-dry transfer cell, BioRad, Hercules, CA, USA) using Trans-Blot Turbo Transfer Buffer (BioRad), detection of protein transfer efficiency was performed using MemCode Reversible Protein Stain Kit (Thermo Fisher Scientific) according to the manufacturer's instructions. Membranes were then blocked with 5\% non-fat milk (Sigma, 70166, Balgach, Switzerland) in TBS-Tween $0.1 \%$, during $1 \mathrm{~h}$ at RT. Then, membranes were incubated with primary antibody (mouse anti-PLP1, 1:500, overnight at $4{ }^{\circ} \mathrm{C}$ ) diluted in TBS-Tween containing 5\% non-fat milk. Membranes were then washed with TBS-Tween $0.1 \%$ and labeled with goat anti-mouse peroxidase-conjugated secondary antibody $2 \mathrm{~h}$ at RT (1/10,000; GE Healthcare). Bands were revealed with a chemiluminescence kit Sirius (BioRad) and scanned with ChemiDoc XRS system (BioRad). Band intensity was quantified with Image J. Data were normalized to total protein levels using MemCode and expressed as percentage of control samples visualized on the same blot. Gels pictures can be found in Figure S3.

\subsection{Statistical Analyses}

Data was normalized to controls and analyzed by using a non-parametric KruskalWallis H test on GraphPad Prism 8 (GraphPad Software, San Diego, CA, USA).

Supplementary Materials: The following are available online at https:/ /www.mdpi.com/article/10 $.3390 /$ ijms22179473/s1.

Author Contributions: Contribution roles have been defined following CRediT (https:/ / casrai.org/ credit/, accessed on 13 July 2021). M.C.: formal analysis, methodology, investigation, writing part of the first draft, reviewing and editing the manuscript. C.R.: investigation and methodology. H.P.: methodology. L.S.: writing (review and editing). T.H.: funding acquisition and conceptualization, review of manuscript. M.-G.Z.: Supervision, validation, writing (review and editing). H.T.H.: conceptualization, supervision, funding acquisition, investigation, and writing (review and editing). D.P.: 
conceptualization, investigation, formal analysis, methodology, supervision, funding acquisition, and writing (first draft). All authors have read and agreed to the published version of the manuscript.

Funding: This study was in part funded by the Colgate-Palmolive Grant for Alternative Research (Helena Hogberg). David Pamies is financially supported by the Swiss Centre for Applied Human Toxicology (SCAHT). Lena Smirnova was supported by an EPA-STAR grant (R839505).

Institutional Review Board Statement: Not applicable.

Informed Consent Statement: Not applicable.

Data Availability Statement: Not applicable.

Acknowledgments: We acknowledge Michael Hughes for editing the manuscript.

Conflicts of Interest: Thomas Hartung, Helena Hogberg and David Pamies are named inventors on a patent by Johns Hopkins University on the production of mini-brains (also called BrainSpheres), which is licensed to AxoSim, New Orleans, LA, USA. They and LS consult AxoSim and Thomas Hartung is a shareholder. Thomas Hartung consults AstraZeneca, American Type Culture Collection (ATCC), InSphero and Apellis Pharmaceuticals on Microphysiological Systems.

\section{References}

1. Baron, W.; Hoekstra, D. On the biogenesis of myelin membranes: Sorting, trafficking and cell polarity. FEBS Lett. 2010, 584, 1760-1770. [CrossRef]

2. Nave, K.A. Myelination and support of axonal integrity by glia. Nature 2010, 468, 244-252. [CrossRef]

3. Fields, R.D. A new mechanism of nervous system plasticity: Activity-dependent myelination. Nat. Rev. Neurosci. 2015, 16, 756-767. [CrossRef]

4. Bourbon-Teles, J.; Bells, S.; Jones, D.K.; Coulthard, E.; Rosser, A.; Metzler-Baddeley, C. Myelin Breakdown in Human Huntington's Disease: Multi-Modal Evidence from Diffusion MRI and Quantitative Magnetization Transfer. Neuroscience 2019, 403, 79-92. [CrossRef] [PubMed]

5. Dean, D.C.; Sojkova, J.; Hurley, S.; Kecskemeti, S.; Okonkwo, O.; Bendlin, B.B.; Theisen, F.; Johnson, S.C.; Alexander, A.L.; Gallagher, C.L. Alterations of Myelin Content in Parkinson's Disease: A Cross-Sectional Neuroimaging Study. PLoS ONE 2016, 11, e0163774. [CrossRef] [PubMed]

6. Nasrabady, S.E.; Rizvi, B.; Goldman, J.E.; Brickman, A.M. White matter changes in Alzheimer's disease: A focus on myelin and oligodendrocytes. Acta Neuropathol. Commun. 2018, 6, 22. [CrossRef] [PubMed]

7. Duncan, I.D.; Radcliff, A.B. Inherited and acquired disorders of myelin: The underlying myelin pathology. Exp. Neurol. 2016, 283, 452-475. [CrossRef]

8. $\quad$ Barak, B.; Zhang, Z.C.; Liu, Y.Y.; Nir, A.; Trangle, S.S.; Ennis, M.; Levandowski, K.M.; Wang, D.Q.; Quast, K.; Boulting, G.L.; et al. Neuronal deletion of Gtf2i, associated with Williams syndrome, causes behavioral and myelin alterations rescuable by a remyelinating drug (vol 22, pg 700, 2019). Nat. Neurosci. 2019, 22, 1197. [CrossRef]

9. Nir, A.; Barak, B. White matter alterations in Williams syndrome related to behavioral and motor impairments. Glia 2021, 69, 5-19. [CrossRef]

10. Barateiro, A.; Fernandes, A. Temporal oligodendrocyte lineage progression: In vitro models of proliferation, differentiation and myelination. BBA-Mol. Cell Res. 2014, 1843, 1917-1929. [CrossRef]

11. Chanoumidou, K.; Mozafari, S.; Baron-Van Evercooren, A.; Kuhlmann, T. Stem cell derived oligodendrocytes to study myelin diseases. Glia 2020, 68, 705-720. [CrossRef]

12. Sim, F.J.; Windrem, M.S.; Goldman, S.A. Fate determination of adult human glial progenitor cells. Neuron Glia Biol. 2009, 5, 45-55. [CrossRef]

13. de Monasterio-Schrader, P.; Jahn, O.; Tenzer, S.; Wichert, S.P.; Patzig, J.; Werner, H.B. Systematic approaches to central nervous system myelin. Cell Mol. Life Sci. 2012, 69, 2879-2894. [CrossRef] [PubMed]

14. Meredith, R.M. Sensitive and critical periods during neurotypical and aberrant neurodevelopment: A framework for neurodevelopmental disorders. Neurosci. Biobehav. Rev. 2015, 50, 180-188. [CrossRef]

15. Landrigan, P.J.; Goldman, L.R. Children's Vulnerability To Toxic Chemicals: A Challenge and Opportunity to Strengthen Health and Environmental Policy. Health Aff. 2011, 30, 842-850. [CrossRef] [PubMed]

16. USEPA. America's Children and the Environment (ACE), 3rd ed.; USEPA: Washington, DC, USA, 2013.

17. Ferguson, A.; Penney, R.; Solo-Gabriele, H. A Review of the Field on Children's Exposure to Environmental Contaminants: A Risk Assessment Approach. Int. J. Environ. Res. Public Health 2017, 14, 65. [CrossRef] [PubMed]

18. Smirnova, L.; Hogberg, H.T.; Leist, M.; Hartung, T. Developmental Neurotoxicity—Challenges in the 21st Century and In Vitro Opportunities. ALTEX Altern. Anim. Exp. 2014, 31, 129-156.

19. Andersen, S.L. Trajectories of brain development: Point of vulnerability or window of opportunity? Neurosci. Biobehav. Rev. 2003, 27, 3-18. [CrossRef]

20. Grandjean, P.; Landrigan, P.J. Neurobehavioural effects of developmental toxicity. Lancet Neurol. 2014, 13, 330-338. [CrossRef] 
21. Boyle, C.A.; Boulet, S.; Schieve, L.A.; Cohen, R.A.; Blumberg, S.J.; Yeargin-Allsopp, M.; Visser, S.; Kogan, M.D. Trends in the Prevalence of Developmental Disabilities in US Children, 1997-2008. Pediatrics 2011, 127, 1034-1042. [CrossRef]

22. Maenner, M.J.; Shaw, K.A.; Baio, J.; Washington, A.; Patrick, M.; DiRienzo, M.; Christensen, D.L.; Wiggins, L.D.; Pettygrove, S.; Andrews, J.G.; et al. Prevalence of Autism Spectrum Disorder Among Children Aged 8 Years-Autism and Developmental Disabilities Monitoring Network, 11 Sites, United States, 2016. MMWR Surveill. Summ. 2020, 69, 1-12. [CrossRef]

23. Danielson, M.L.; Bitsko, R.H.; Ghandour, R.M.; Holbrook, J.R.; Kogan, M.D.; Blumberg, S.J. Prevalence of Parent-Reported ADHD Diagnosis and Associated Treatment Among U.S. Children and Adolescents, 2016. J. Clin. Child. Adolesc. Psychol. 2018, 47, 199-212. [CrossRef]

24. Hansen, S.N.; Schendel, D.E.; Parner, E.T. Explaining the increase in the prevalence of autism spectrum disorders: The proportion attributable to changes in reporting practices. JAMA Pediatr. 2015, 169, 56-62. [CrossRef] [PubMed]

25. Visser, S.N.; Danielson, M.L.; Bitsko, R.H.; Holbrook, J.R.; Kogan, M.D.; Ghandour, R.M.; Perou, R.; Blumberg, S.J. Trends in the Parent-Report of Health Care Provider-Diagnosed and Medicated Attention-Deficit/Hyperactivity Disorder: United States, 2003-2011. J. Am. Acad. Child. Psychiatry 2014, 53, 34-46. [CrossRef]

26. Ardhanareeswaran, K.; Mariani, J.; Coppola, G.; Abyzov, A.; Vaccarino, F.M. Human induced pluripotent stem cells for modelling neurodevelopmental disorders. Nat. Rev. Neurol. 2017, 13, 265-278. [CrossRef]

27. Grandjean, P.; Landrigan, P.J. Developmental neurotoxicity of industrial chemicals. Lancet 2006, 368, 2167-2178. [CrossRef]

28. Heyer, D.B.; Meredith, R.M. Environmental toxicology: Sensitive periods of development and neurodevelopmental disorders. Neurotoxicology 2017, 58, 23-41. [CrossRef] [PubMed]

29. Schettler, T. Toxic threats to neurologic development of children. Environ. Health Perspect. 2001, 109, 813-816. [CrossRef]

30. Bondy, S.C.; Campbell, A. Developmental neurotoxicology. J. Neurosci. Res. 2005, 81, 605-612. [CrossRef]

31. Lanphear, B.P.; Hornung, R.; Khoury, J.; Yolton, K.; Baghurstl, P.; Bellinger, D.C.; Canfield, R.L.; Dietrich, K.N.; Bornschein, R.; Greene, T.; et al. Low-level environmental lead exposure and children's intellectual function: An international pooled analysis. Environ. Health Perspect. 2005, 113, 894-899. [CrossRef] [PubMed]

32. Kadereit, S.; Zimmer, B.; van Thriel, C.; Hengstler, J.G.; Leist, M. Compound selection for in vitro modeling of developmental neurotoxicity. Front. Biosci-Landmark 2012, 17, 2442-2460. [CrossRef]

33. Makris, S.L.; Raffaele, K.; Allen, S.; Bowers, W.J.; Hass, U.; Alleva, E.; Calamandrei, G.; Sheets, L.; Amcoff, P.; Delrue, N.; et al. A Retrospective Performance Assessment of the Developmental Neurotoxicity Study in Support of OECD Test Guideline 426. Environ. Health Perspect 2009, 117, 17-25. [CrossRef] [PubMed]

34. Bal-Price, A.; Crofton, K.M.; Leist, M.; Allen, S.; Arand, M.; Buetler, T.; Delrue, N.; FitzGerald, R.E.; Hartung, T.; Heinonen, T.; et al. International STakeholder NETwork (ISTNET): Creating a developmental neurotoxicity (DNT) testing road map for regulatory purposes. Arch. Toxicol. 2015, 89, 269-287. [CrossRef] [PubMed]

35. Crofton, K.M.; Mundy, W.R.; Shafer, T.J. Developmental neurotoxicity testing: A path forward. Congenit. Anom. 2012, 52, 140-146. [CrossRef] [PubMed]

36. Bhattacharya, S.; Zhang, Q.; Carmichael, P.L.; Boekelheide, K.; Andersen, M.E. Toxicity Testing in the 21(st) Century: Defining New Risk Assessment Approaches Based on Perturbation of Intracellular Toxicity Pathways. PLoS ONE 2011, 6, e20887. [CrossRef]

37. Leist, M.; Hartung, T.; Nicotera, P. The dawning of a new age of toxicology. ALTEX-Altern. Tierexp. 2008, 25, 103-114. [CrossRef]

38. Hartung, T.; Leist, M. Food for thought ... on the evolution of toxicology and the phasing out of animal testing. ALTEX 2008, 25, 91-102. [CrossRef]

39. Hartung, T.; McBride, M. Food for Thought ... on mapping the human toxome. ALTEX 2011, 28, 83-93. [CrossRef]

40. Leist, M.; Hasiwa, N.; Rovida, C.; Daneshian, M.; Basketter, D.; Kimber, I.; Clewell, H.; Gocht, T.; Goldberg, A.; Busquet, F.; et al. Consensus Report on the Future of Animal-Free Systemic Toxicity Testing. ALTEX-Altern. Anim. Exp. 2014, 31, 341-356. [CrossRef] [PubMed]

41. Bayer, S.A.; Altman, J.; Russo, R.J.; Zhang, X. Timetables of Neurogenesis in the Human Brain Based on Experimentally Determined Patterns in the Rat. Neurotoxicology 1993, 14, 83-144.

42. Rice, D.; Barone, S., Jr. Critical periods of vulnerability for the developing nervous system: Evidence from humans and animal models. Environ. Health Perspect. 2000, 108 (Suppl. 3), 511-533. [CrossRef] [PubMed]

43. Fritsche, E.; Alm, H.; Baumann, J.; Geerts, L.; Håkansson, H.; Masjosthusmann, S.; Witters, H. Literature review on in vitro and alternative Developmental Neurotoxicity (DNT) testing methods. EFSA Support. Publ. 2015, 12, 778E. [CrossRef]

44. Chan, J.R.; Watkins, T.A.; Cosgaya, J.M.; Zhang, C.Z.; Chen, L.; Reichardt, L.F.; Shooter, E.M.; Barres, B.A. NGF controls axonal receptivity to myelination by Schwann cells or oligodendrocytes. Neuron 2004, 43, 183-191. [CrossRef] [PubMed]

45. Lariosa-Willingham, K.D.; Rosler, E.S.; Tung, J.S.; Dugas, J.C.; Collins, T.L.; Leonoudakis, D. Development of a central nervous system axonal myelination assay for high throughput screening. BMC Neurosci. 2016, 17, 16. [CrossRef]

46. Wang, Z.; Colognato, H.; Ffrench-Constant, C. Contrasting effects of mitogenic growth factors on myelination in neuronoligodendrocyte co-cultures. Glia 2007, 55, 537-545. [CrossRef] [PubMed]

47. Pang, Y.; Zheng, B.; Kimberly, S.L.; Cai, Z.; Rhodes, P.G.; Lin, R.C. Neuron-oligodendrocyte myelination co-culture derived from embryonic rat spinal cord and cerebral cortex. Brain Behav. 2012, 2, 53-67. [CrossRef]

48. Ristola, M.; Sukki, L.; Azevedo, M.M.; Seixas, A.I.; Relvas, J.B.; Narkilahti, S.; Kallio, P. A compartmentalized neuronoligodendrocyte co-culture device for myelin research: Design, fabrication and functionality testing. J. Micromech. Microeng. 2019, 29, 065009. [CrossRef] 
49. Clark, A.J.; Kaller, M.S.; Galino, J.; Willison, H.J.; Rinaldi, S.; Bennett, D.L.H. Co-cultures with stem cell-derived human sensory neurons reveal regulators of peripheral myelination. Brain 2017, 140, 898-913. [CrossRef]

50. Barateiro, A.; Domingues, H.S.; Fernandes, A.; Relvas, J.B.; Brites, D. Rat Cerebellar Slice Cultures Exposed to Bilirubin Evidence Reactive Gliosis, Excitotoxicity and Impaired Myelinogenesis that Is Prevented by AMPA and TNF-alpha Inhibitors. Mol. Neurobiol. 2014, 49, 424-439. [CrossRef]

51. Hill, R.A.; Medved, J.; Patel, K.D.; Nishiyama, A. Organotypic Slice Cultures to Study Oligodendrocyte Dynamics and Myelination. JoVE-J. Vis. Exp. 2014, 90, e51835. [CrossRef]

52. Miron, V.E.; Ludwin, S.K.; Darlington, P.J.; Jarjour, A.A.; Soliven, B.; Kennedy, T.E.; Antel, J.P. Fingolimod (FTY720) Enhances Remyelination Following Demyelination of Organotypic Cerebellar Slices. Am. J. Pathol. 2010, 176, 2682-2694. [CrossRef]

53. Zurich, M.G.; Stanzel, S.; Kopp-Schneider, A.; Prieto, P.; Honegger, P. Evaluation of aggregating brain cell cultures for the detection of acute organ-specific toxicity. Toxicol. In Vitro 2013, 27, 1416-1424. [CrossRef] [PubMed]

54. Zurich, M.G.; Honegger, P.; Schilter, B.; Costa, L.G.; Monnet-Tschudi, F. Use of aggregating brain cell cultures to study developmental effects of organophosphorus insecticides. Neurotoxicology 2000, 21, 599-605. [PubMed]

55. Honegger, P.; Zurich, M.G. Preparation and Use of Serum-Free Aggregating Brain Cell Cultures for Routine Neurotoxicity Screening. Neuromethods 2011, 56, 105-128. [CrossRef]

56. Guentert-Lauber, B.; Monnet-Tschudi, F.; Omlin, F.X.; Favrod, P.; Honegger, P. Serum-free aggregate cultures of rat CNS glial cells: Biochemical, immunocytochemical and morphological characterization. Dev. Neurosci. 1985, 7, 33-44. [CrossRef] [PubMed]

57. Kerman, B.E.; Kim, H.J.; Padmanabhan, K.; Mei, A.; Georges, S.; Joens, M.S.; Fitzpatrick, J.A.J.; Jappelli, R.; Chandross, K.J.; August, P.; et al. In vitro myelin formation using embryonic stem cells. Development 2015, 142, 2213-2225. [CrossRef] [PubMed]

58. Chesnut, M.; Hartung, T.; Hogberg, H.; Pamies, D. Human Oligodendrocytes and Myelin In Vitro to Evaluate Developmental Neurotoxicity. Int. J. Mol. Sci. 2021, 22, 7929. [CrossRef] [PubMed]

59. Madhavan, M.; Nevin, Z.S.; Shick, H.E.; Garrison, E.; Clarkson-Paredes, C.; Karl, M.; Clayton, B.L.L.; Factor, D.C.; Allan, K.C.; Barbar, L.; et al. Induction of myelinating oligodendrocytes in human cortical spheroids. Nat. Methods 2018, 15, 700-706. [CrossRef]

60. Kim, H.; Xu, R.; Padmashri, R.; Dunaevsky, A.; Liu, Y.; Dreyfus, C.F.; Jiang, P. Pluripotent Stem Cell-Derived Cerebral Organoids Reveal Human Oligodendrogenesis with Dorsal and Ventral Origins. Stem Cell Rep. 2019, 12, 890-905. [CrossRef]

61. Pamies, D.; Barreras, P.; Block, K.; Makri, G.; Kumar, A.; Wiersma, D.; Smirnova, L.; Zhang, C.; Bressler, J.; Christian, K.M.; et al. A Human Brain Microphysiological System Derived from Induced Pluripotent Stem Cells to Study Neurological Diseases and Toxicity. ALTEX-Altern. Anim. Exp. 2017, 34, 362-376. [CrossRef]

62. Marton, R.M.; Miura, Y.; Sloan, S.A.; Li, Q.Y.; Revah, O.; Levy, R.J.; Huguenard, J.R.; Pasca, S.P. Differentiation and maturation of oligodendrocytes in human three-dimensional neural cultures. Nat. Neurosci. 2019, 22, 484-491. [CrossRef] [PubMed]

63. James, O.G.; Selvaraj, B.T.; Magnani, D.; Burr, K.; Connick, P.; Barton, S.K.; Vasistha, N.A.; Hampton, D.W.; Story, D.; Smigiel, R.; et al. iPSC-derived myelinoids to study myelin biology of humans. Dev. Cell 2021, 56, 1346-1358.e1346. [CrossRef] [PubMed]

64. Hogberg, H.T.; Bressler, J.; Christian, K.M.; Harris, G.; Makri, G.; O’Driscoll, C.; Pamies, D.; Smirnova, L.; Wen, Z.X.; Hartung, T. Toward a 3D model of human brain development for studying gene/environment interactions. Stem Cell Res. Ther. 2013, 4, S4. [CrossRef]

65. Plummer, S.; Wallace, S.; Ball, G.; Lloyd, R.; Schiapparelli, P.; Quinones-Hinojosa, A.; Hartung, T.; Pamies, D. A Human iPSCderived 3D platform using primary brain cancer cells to study drug development and personalized medicine. Sci. Rep. UK 2019, 9, 1407. [CrossRef]

66. Zhou, Q.J.; Nino, D.F.; Yamaguchi, Y.; Wang, S.X.; Fulton, W.B.; Jia, H.P.; Lu, P.; Prindle, T.; Pamies, D.; Morris, M.; et al. Necrotizing enterocolitis induces T lymphocyte-mediated injury in the developing mammalian brain. Sci. Transl. Med. 2021, 13, eaay6621. [CrossRef]

67. Leite, P.E.C.; Pereira, M.R.; Harris, G.; Pamies, D.; dos Santos, L.M.G.; Granjeiro, J.M.; Hogberg, H.T.; Hartung, T.; Smirnova, L. Suitability of 3D human brain spheroid models to distinguish toxic effects of gold and poly-lactic acid nanoparticles to assess biocompatibility for brain drug delivery. Part. Fibre Toxicol. 2019, 16, 22. [CrossRef]

68. Pamies, D.; Block, K.; Lau, P.; Gribaldo, L.; Pardo, C.A.; Barreras, P.; Smirnova, L.; Wiersma, D.; Zhao, L.; Harris, G.; et al. Rotenone exerts developmental neurotoxicity in a human brain spheroid model. Toxicol. Appl. Pharm. 2018, 354, 101-114. [CrossRef] [PubMed]

69. Zhong, X.; Harris, G.; Smirnova, L.; Zufferey, V.; Sa, R.; Baldino Russo, F.; Baleeiro Beltrao Braga, P.C.; Chesnut, M.; Zurich, M.G.; Hogberg, H.T.; et al. Antidepressant Paroxetine Exerts Developmental Neurotoxicity in an iPSC-Derived 3D Human Brain Model. Front. Cell Neurosci. 2020, 14, 25. [CrossRef]

70. Cammer, W. The neurotoxicant, cuprizone, retards the differentiation of oligodendrocytes in vitro. J. Neurol. Sci. 1999, 168, 116-120. [CrossRef]

71. Gospe, S.M.; Zhou, S.S. Toluene abuse embryopathy: Longitudinal neurodevelopmental effects of prenatal exposure to toluene in rats. Reprod. Toxicol. 1998, 12, 119-126. [CrossRef]

72. Tiwari, S.K.; Agarwal, S.; Chauhan, L.K.; Mishra, V.N.; Chaturvedi, R.K. Bisphenol-A impairs myelination potential during development in the hippocampus of the rat brain. Mol. Neurobiol. 2015, 51, 1395-1416. [CrossRef] 
73. Xu, X.B.; Fan, S.J.; He, Y.; Ke, X.; Song, C.; Xiao, Y.; Zhang, W.H.; Zhang, J.Y.; Yin, X.P.; Kato, N.; et al. Loss of Hippocampal Oligodendrocytes Contributes to the Deficit of Contextual Fear Learning in Adult Rats Experiencing Early Bisphenol A Exposure. Mol. Neurobiol. 2017, 54, 4524-4536. [CrossRef]

74. Dach, K.; Bendt, F.; Huebenthal, U.; Giersiefer, S.; Lein, P.J.; Heuer, H.; Fritsche, E. BDE-99 impairs differentiation of human and mouse NPCs into the oligodendroglial lineage by speciesspecific modes of action. Sci Rep. UK 2017, 7, 4861. [CrossRef]

75. Schreiber, T.; Gassmann, K.; Gotz, C.; Hubenthal, U.; Moors, M.; Krause, G.; Merk, H.F.; Nguyen, N.H.; Scanlan, T.S.; Abel, J.; et al. Polybrominated Diphenyl Ethers Induce Developmental Neurotoxicity in a Human in Vitro Model: Evidence for Endocrine Disruption. Environ. Health Perspect. 2010, 118, 572-578. [CrossRef] [PubMed]

76. Bichenkov, E.; Ellingson, J.S. Ethanol exerts different effects on myelin basic protein and $2^{\prime}, 3^{\prime}$-cyclic nucleotide $3^{\prime}$ phosphodiesterase expression in differentiating CG-4 oligodendrocytes. Brain Res. Dev. Brain Res. 2001, 128, 9-16. [CrossRef]

77. Miller, M.W.; al-Rabiai, S. Effects of prenatal exposure to ethanol on the number of axons in the pyramidal tract of the rat. Alcohol. Clin. Exp. Res. 1994, 18, 346-354. [CrossRef]

78. Roskam, S.; Koch, M. Effects of neonatal and peripubertal ethanol treatment on various aspects of adult rat behavior and brain anatomy. Int. J. Dev. Neurosci. 2009, 27, 249-256. [CrossRef]

79. Zoeller, R.T.; Butnariu, O.V.; Fletcher, D.L.; Riley, E.P. Limited postnatal ethanol exposure permanently alters the expression of mRNAS encoding myelin basic protein and myelin-associated glycoprotein in cerebellum. Alcohol. Clin. Exp. Res. 1994, 18, 909-916. [CrossRef]

80. Padhi, B.K.; Pelletier, G. Perturbation of myelin basic protein (Mbp) splice variant expression in developing rat cerebellum following perinatal exposure to methylmercury. Toxicol. Lett. 2012, 213, 374-380. [CrossRef]

81. Wang, Q.; Lai, N.L.; Wang, X.; Guo, Y.; Lam, P.K.; Lam, J.C.; Zhou, B. Bioconcentration and transfer of the organophorous flame retardant 1,3-dichloro-2-propyl phosphate causes thyroid endocrine disruption and developmental neurotoxicity in zebrafish larvae. Environ. Sci. Technol. 2015, 49, 5123-5132. [CrossRef]

82. Azeez, I.A.; Olopade, F.; Laperchia, C.; Andrioli, A.; Scambi, I.; Onwuka, S.K.; Bentivoglio, M.; Olopade, J.O. Regional Myelin and Axon Damage and Neuroinflammation in the Adult Mouse Brain After Long-Term Postnatal Vanadium Exposure. J. Neuropathol. Exp. Neurol. 2016, 75, 843-854. [CrossRef] [PubMed]

83. Soazo, M.; Garcia, G.B. Vanadium exposure through lactation produces behavioral alterations and CNS myelin deficit in neonatal rats. Neurotoxicol. Teratol. 2007, 29, 503-510. [CrossRef] [PubMed]

84. Todorich, B.; Olopade, J.O.; Surguladze, N.; Zhang, X.; Neely, E.; Connor, J.R. The mechanism of vanadium-mediated developmental hypomyelination is related to destruction of oligodendrocyte progenitors through a relationship with ferritin and iron. Neurotox. Res. 2011, 19, 361-373. [CrossRef]

85. Deng, W.; McKinnon, R.D.; Poretz, R.D. Lead exposure delays the differentiation of oligodendroglial progenitors in vitro. Toxicol. Appl. Pharmacol. 2001, 174, 235-244. [CrossRef]

86. Huang, F.; Schneider, J.S. Effects of lead exposure on proliferation and differentiation of neural stem cells derived from different regions of embryonic rat brain. Neurotoxicology 2004, 25, 1001-1012. [CrossRef] [PubMed]

87. Torkildsen, O.; Brunborg, L.A.; Myhr, K.M.; Bo, L. The cuprizone model for demyelination. Acta Neurol. Scand. 2008, 117, 72-76. [CrossRef]

88. Matsushima, G.K.; Morell, P. The neurotoxicant, cuprizone, as a model to study demyelination and remyelination in the central nervous system. Brain Pathol. 2001, 11, 107-116. [CrossRef]

89. Venturini, G. Enzymic activities and sodium, potassium and copper concentrations in mouse brain and liver after cuprizone treatment in vivo. J. Neurochem. 1973, 21, 1147-1151. [CrossRef]

90. Stapleton, H.M.; Klosterhaus, S.; Eagle, S.; Fuh, J.; Meeker, J.D.; Blum, A.; Webster, T.F. Detection of organophosphate flame retardants in furniture foam and U.S. house dust. Environ. Sci. Technol. 2009, 43, 7490-7495. [CrossRef]

91. Dishaw, L.V.; Hunter, D.L.; Padnos, B.; Padilla, S.; Stapleton, H.M. Developmental exposure to organophosphate flame retardants elicits overt toxicity and alters behavior in early life stage zebrafish (Danio rerio). Toxicol. Sci. Off. J. Soc. Toxicol. 2014, 142, 445-454. [CrossRef]

92. Aschner, M.; Ceccatelli, S.; Daneshian, M.; Fritsche, E.; Hasiwa, N.; Hartung, T.; Hogberg, H.T.; Leist, M.; Li, A.; Mundi, W.R.; et al. Reference compounds for alternative test methods to indicate developmental neurotoxicity (DNT) potential of chemicals: Example lists and criteria for their selection and use. ALTEX 2017, 34, 49-74. [CrossRef] [PubMed]

93. Parepally, J.M.; Mandula, H.; Smith, Q.R. Brain uptake of nonsteroidal anti-inflammatory drugs: Ibuprofen, flurbiprofen, and indomethacin. Pharm. Res. 2006, 23, 873-881. [CrossRef]

94. Sandstrom, J.; Eggermann, E.; Charvet, I.; Roux, A.; Toni, N.; Greggio, C.; Broyer, A.; Monnet-Tschudi, F.; Stoppini, L. Development and characterization of a human embryonic stem cell-derived 3D neural tissue model for neurotoxicity testing. Toxicol In Vitro 2017, 38, 124-135. [CrossRef]

95. Fancy, S.P.; Chan, J.R.; Baranzini, S.E.; Franklin, R.J.; Rowitch, D.H. Myelin regeneration: A recapitulation of development? Annu. Rev. Neurosci. 2011, 34, 21-43. [CrossRef] [PubMed]

96. Holzhütter, H.; Archer, G.; Dami, N.; Lovell, D.P.; Saltelli, A.; Sjostrom, M. Recommendations for the Application of Biostatistical Methods During the Development and Validation of Alternative Toxicological Methods: ECVAM Biostatistics Task Force Report 1. ATLA 1996, 24, 511-530. [CrossRef] 
97. Chiang, C.H.; Su, Y.; Wen, Z.; Yoritomo, N.; Ross, C.A.; Margolis, R.L.; Song, H.; Ming, G.I. Integration-free induced pluripotent stem cells derived from schizophrenia patients with a DISC1 mutation. Mol. Psychiatr. 2011, 16, 358-360. [CrossRef]

98. Wen, Z.X.; Nguyen, H.N.; Guo, Z.Y.; Lalli, M.A.; Wang, X.Y.; Su, Y.J.; Kim, N.S.; Yoon, K.J.; Shin, J.; Zhang, C.; et al. Synaptic dysregulation in a human iPS cell model of mental disorders. Nature 2014, 515, 414. [CrossRef]

99. Livak, K.J.; Schmittgen, T.D. Analysis of relative gene expression data using real-time quantitative PCR and the 2(-Delta Delta C(T)) Method. Methods 2001, 25, 402-408. [CrossRef] [PubMed] 